\title{
Paleoambiente da Formação Prosperança, embasamento neoproterozóico da Bacia do Amazonas
}

\author{
Roberto Cesar de Mendonça Barbosa ${ }^{1}$ \& Afonso César Rodrigues Nogueira ${ }^{2}$
}

\begin{abstract}
Resumo Rochas de idade neoproterozóica da Formação Prosperança, cobertura sedimentar da porção sul do Escudo das Guianas, são pobremente expostas quando comparadas com o registro paleozóico das bacias do Amazonas e Solimões. A Formação Prosperança consiste em conglomerados, arenitos arcosianos e pelitos que preenchem grábens no embasamento. Esta unidade é sotoposta por rochas carbonáticas da Formação Acarí (Neoproterozóico), observada apenas em subsuperfície, que agrupadas, representam o embasamento sedimentar das bacias paleozóicas produtoras de óleo da Amazônia. A precisa caracterização e reconstrução paleoambiental da Formação Prosperança são essenciais para a distinção entre unidades do embasamento sedimentar e paleozóicas. A análise estratigráfica foi realizada na região do baixo rio Negro, Estado do Amazonas. A Formação Prosperança consiste em quatro associações de fácies que foram interpretadas como produto de um sistema flúvio-deltaico: prodelta/lacustre, frente deltaica, foreshore/shoreface e planície braided distal. Camadas tabulares de pelitos distribuídos por quilômetros sugerem uma bacia sedimentar de provável origem lacustre/mar restrito. Lobos deltaicos complexamente estruturados foram alimentados por distributários braided que migravam para SE. Arenitos gerados sob condições de fluxo oscilatório/combinado são compatíveis com depósitos de face litorânea. Arenitos com estratificação cruzada e planar estão relacionados com a migração de dunas subaquosas associadas a processos fluviais braided. Camadas lenticulares de conglomerados e arenitos com estratificação cruzada e planar, de possível idade paleozóica, sobrepõem a Formação Prosperança erosivamente. Essas camadas são produtos de um sistema fluvial braided proximal que migrava para NW, sentido inverso dos valores de paleocorrentes dos arenitos Prosperança.
\end{abstract}

Palavras-chave: Escudo das Guianas, Formação Prosperança, sistema flúvio-deltaico.

\begin{abstract}
Paleoenvironment of Prosperança Formation, neoproterozoic basement of Amazonas Basin. The Neoproterozoic Prosperança Formation represents a sedimentary cover of southern Guyana Shield and is poorly exposed when contrasted with Paleozoic record of Amazonas and Solimões basins. Conglomerates, arkosic sandstones and mudstones are the characteristics deposits filling basement grabens. This unit is overlain unconformably by neoproterozoic carbonate rocks of Acarí Formation (observed only in cores). These formations represent the sedimentary basement of oil producing Paleozoic basins of the Amazon region. The precise characterization and paleoenvironmental reconstruction of Prosperança Formation are important for their distinction from Paleozoic units. Stratigraphic analysis was carried out at lower Negro River, State of Amazonas. Four facies associations were interpreted as products of a fluvial-deltaic system: prodelta/lacustrine, delta front, foreshore/ shoreface and distal braided plain. Mudstones distributed along several kilometers suggest a sedimentary basin probably of lacustrine/restricted sea origins. Complex structured deltaic lobes were fed by braided distributaries that migrated mainly to SE. Sandstones generated under oscillatory/combined flux are conformable with shoreline deposits. Planar to trough cross-bedded sandstones are related to migration of subaqueous dunes, associated to fluvial-braided processes. Lenses of conglomerate, planar to trough cross-bedded sandstones, possibly of paleozoic age, which overlies unconformably the Prosperança Formation migrated to NW as product of proximal braided plain system and is in contrast to the S-directed cross-stratification of the Prosperança sandstones.
\end{abstract}

Keywords: Guyana Shield, Prosperança Formation, fluvial-deltaic system.

INTRODUÇÃO Depósitos siliciclásticos de idade pré-cambriana da Formação Prosperança ocorrem no sul do Escudo das Guianas e constituem parte do embasamento das bacias paleozóicas da Amazônia Ocidental. Empresas petrolíferas em atividade nestas bacias têm se deparado com a problemática na distinção entre a Formação Prosperança e os depósitos do Paleozóico Infe- rior, tanto em superfície quanto em subsuperfície, principalmente quando são encontrados em contato. De fato, a natureza siliciclástica grossa e a ausência de fósseis na Formação Prosperança, bem como de litotipos ideais para datação, como por exemplo, rochas vulcânicas e vulcanoclásticas intercaladas, dificultam a distinção destas unidades. O entendimento da história sedimentar 
da Formação Prosperança é um dos pontos importantes para estabelecer critérios para esta diferenciação.

Estudos preliminares na Formação Prosperança datam do final século passado (Castro et al. 1988) e são informações de cunho exclusivamente litológicas, sem uma interpretação mais precisa das fácies sedimentares e dos sistemas deposicionais. A análise de fácies ( $c f$. Walker 1990, 1992) realizada em exposições da Formação Prosperança na região do baixo rio Negro, Estado do Amazonas, permitiu identificar um sistema flúviodeltaico desenvolvido no sul do Escudo das Guianas durante o Neoproterozóico (Fig. 1). A reconstrução da história sedimentar que precedeu a implantação das bacias paleozóicas amazônicas forneceu implicações importantes na reconstituição paleogeográfica desta parte da Amazônia Ocidental.

CONTEXTO GEOLÓGICO Rochas da Formação Prosperança afloram nas proximidades da região do Gráben Invertido do Purus (GIP), oeste da cidade de Manaus (Wanderley Filho 1991, Fig. 2). O GIP é uma feição estrutural arqueada orientada aproximadamente na direção
NW-SE que separa as bacias do Amazonas e Solimões. Essa estrutura foi reconhecida através de mapas de isópacas, seções geológicas, sísmicas e gravimétricas que condizem com rochas com baixa densidade, correlatas ao Grupo Purus (Formação Prosperança e Acarí) (Caputo et al. 1972, Wanderley Filho 1991). Dados de poços sugerem embasamento com idades de 1.00 a $1.90 \mathrm{Ga}$, similares as encontradas no Supergrupo Uatumã (Wanderley Filho 1991). Durante o Fanerozóico o GIP comportou-se como zona compartimental, controlando em particular a migração lateral dos sistemas deposicionais das bacias do Amazonas e Solimões, bem como as incursões marinhas (Mapes 2009, Hoorn et al. 2010).

O GIP pode compor junto com a Serra do Cachimbo uma única feição que foi obliterada no início do Paleozóico pelo desenvolvimento da Bacia do Amazonas, de direção SSW-NNE (Wanderley Filho 1991). Faltam estudos estratigráficos que comprovem esta correlação com rochas da Formação Prosperança.

A Formação Prosperança alcança espessuras superiores a $1.000 \mathrm{~m}$ sobrepondo-se as rochas da Província Ventuari-Tapajós $(1.95-1.80 \mathrm{Ga})$ e Rio Negro-

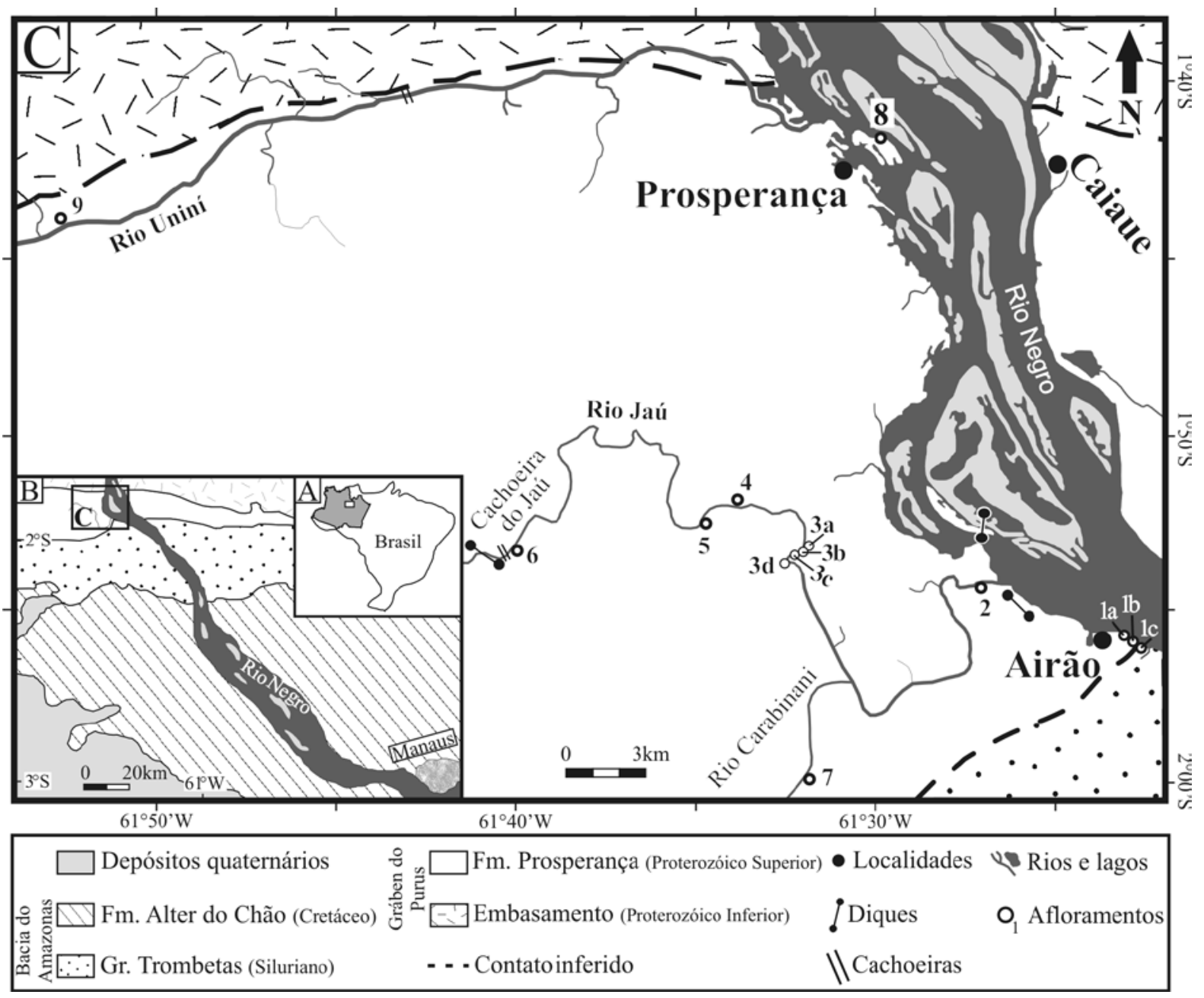

Figura 1 - Geologia e localização da região do baixo rio Negro. A) Disposição geográfica da área investigada. B) Contexto e distribuição das unidades geológicas. C) Mapa geológico e localização das exposições analisadas (Modificado de CPRM 2002). 


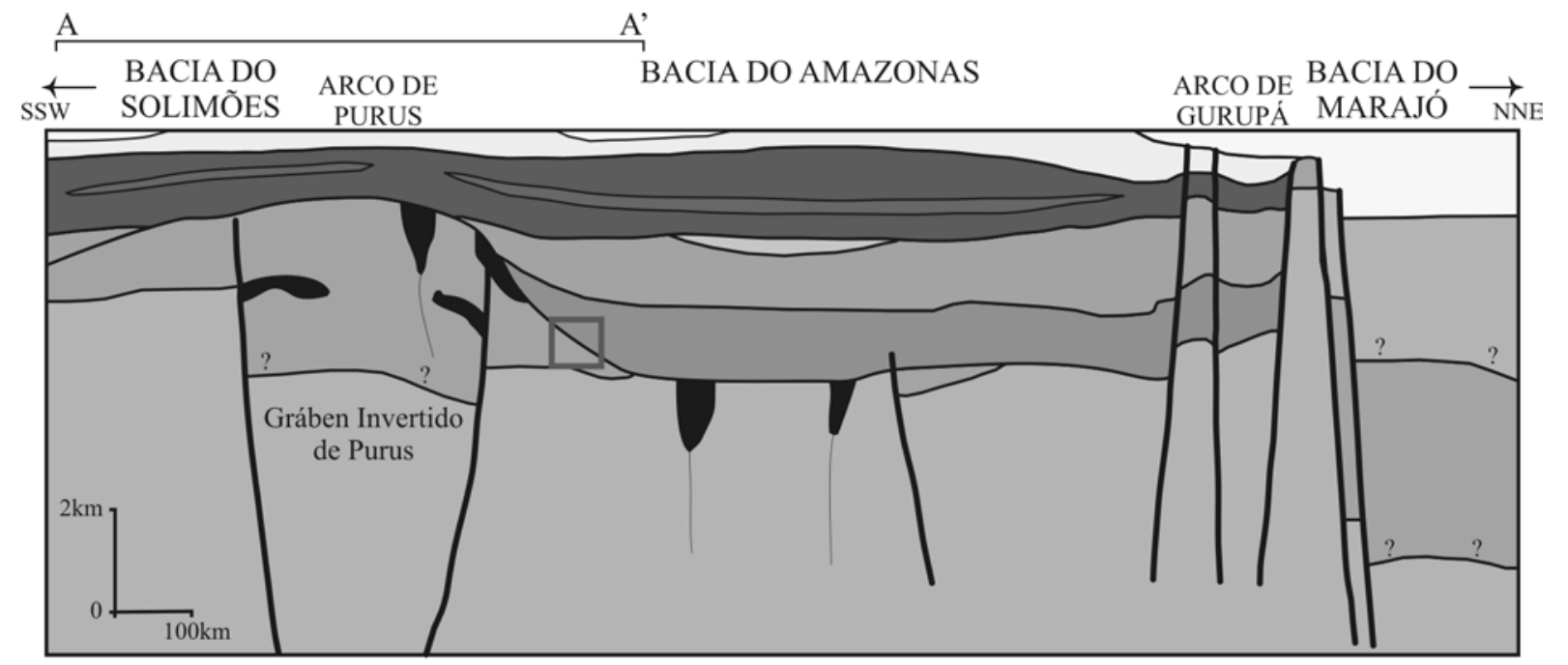

\begin{tabular}{|llll|}
\hline LEGENDAS & $\square$ Vulcânicas & Neo-viseano & $\square$ Pré-cretáceo-paleozóico \\
$\square$ Embasamento Cristalino & $\square$ Ordoviciano-devoniano & Pensilvano-permiano & $\square$ Cretáceo \\
$\square$ Proterozóico & $\square$ Devoniano-tournasiano & Triássico (diabásio) & $\square$ Cenozóico \\
\hline
\end{tabular}

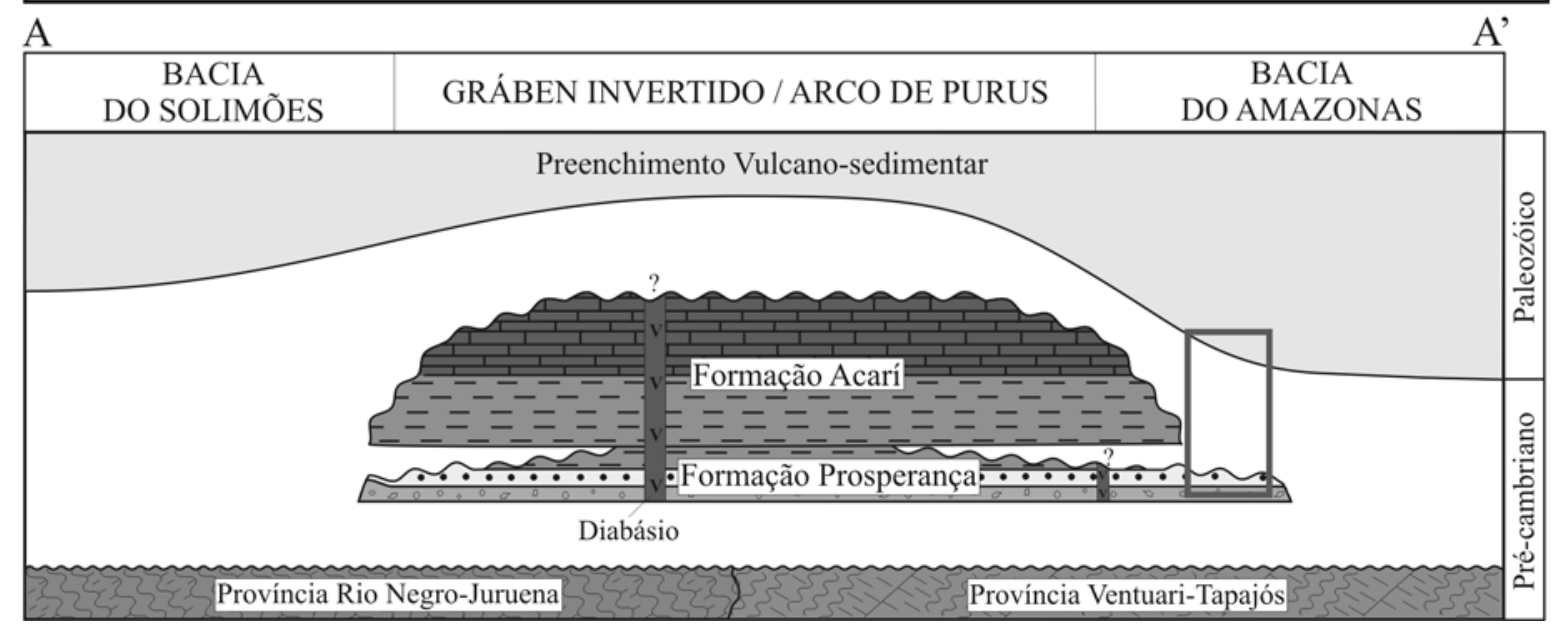

Figura 2 - Seção longitudinal das bacias do Solimões, Amazonas e Marajó com a disposição das seqüências sedimentares e eventos magmáticos. Na região do baixo rio Negro, rochas da Formação Prosperança estão inseridas no Gráben Invertido de Purus. O perfil A-A' destaca a estratigrafia do embasamento pré-cambriano na região do Arco de Purus. Os retângulos enfatizam o intervalo analisado (Modificado de Eiras 1996, Cunha et al. 2007, Wanderley Filho et al. 2007).

Juruena $(1.80-1.55 \mathrm{Ga})$, sendo sotoposta em discordância erosiva, por rochas da Formação Acarí (Proterozóico) e da Formação Nhamundá (Siluriano) (Wanderley Filho 1991, Cunha et al. 2007, Fig. 2).

A datação de grãos de zircão detrítico em afloramentos da Formação Prosperança ao longo da rodovia BR-174 indicaram idade mínima de sedimentação de $1.02 \pm 7 \mathrm{Ga}$ (CPRM 2002, método de evaporação Pb$\mathrm{Pb}$ ). Por outro lado, diques de diabásio datados entre 1.10 e $1.40 \mathrm{Ga}$ sugerem que a Formação Prosperança poderia ser mais antiga (Caputo et al. 1972, Montalvão \& Bezerra 1985). Além da ausência de fósseis, a falta de estudos estratigráficos detalhados não permite avançar a discussão sobre a idade considerada como Proterozóica. No entanto, quando comparada às unidades sedimentares pré-cambrianas do Escudo das Guianas, a Formação Prosperança não é correlata ao Supergrupo
Roraima (Paleoproterozóico) e nem à Formação Urupi (Mesoproterozóico), o que indica um provável trend de subsidência para o sul do Escudo das Guianas, sugerindo idades mais novas para a Formação Prosperança (Neoproterozóico?).

\section{A SUCESSÃO SEDIMENTAR NA REGIÃO DO} BAIXO RIO NEGRO A sucessão sedimentar encontrada na região do baixo rio Negro é constituída pela Formação Prosperança e Grupo Trombetas (?) e expõem-se nas escarpas dos rios Unini, Negro, Jaú e Carabinani (Fig. 1). Os afloramentos alcançam até $10 \mathrm{~m}$ de altura e são isolados, no entanto em algumas localidades são lateralmente contínuos por dezenas de metros. A densa cobertura vegetal e espessos perfis de solo também contribuem para a escassez de afloramentos. A Formação Prosperança é recoberta em caráter erosivo 
por rochas da base do Grupo Trombetas (?) (Fig. 3). A sucessão estudada consiste de 14 fácies obtidas a partir da descrição de 14 seções colunares que foram agrupadas em cinco associações de fácies representativas de um sistema flúvio-deltaico (Formação Prosperança) e fluvial braided (Grupo Trombetas) (Tab. 1 e Fig. 4). A correlação entre as seções colunares foi efetuada com base no nível do rio Negro que, apesar de ser uma superfície erosiva, é um horizonte comum em todas as seções colunares. As fácies são geralmente friáveis e exibem coloração avermelhada e acinzentada.

Associação de fácies 1 (AF1) - prodelta A AF1 engloba as fácies pelito laminado (Pl) e pelito com lentes de arenito com laminação cruzada (Pac). Consistem em corpos tabulares e lateralmente contínuos por centenas de metros que podem alcançar $2 \mathrm{~m}$ de espessura, expostos na porção basal dos afloramentos dos rios Negro (pontos 1a, Fig. 1) e Carabinani (ponto 7) ou intercalados a depósitos de frente deltaica (AF2) no rio Jaú (Pontos 3a, b, d e 5). Nos pontos 3a, 5 e 7, marcam a base de ciclos coarsening upward (Fig. 5).

O predomínio de fácies pelíticas sugere um ambiente dominado por processos de suspensão (Fig. 5A), contudo a fácies Pac indica um ambiente dominado por processos de suspensão com influxo periódico de areia relacionado à barras distais (Figs. 5B, C, D e E). A alternância entre processos de suspensão e tração é relacionada à ação da maré (Reineck \& Singh 1980). Pelitos laminados e com lentes de arenitos com laminação cruzada sugerem uma bacia de sedimentação de provável origem lacustre/lagunar influenciada por maré.

Associação de fácies 2 (AF2) - frente deltaica A AF2 consiste das fácies arenito com estratificação cruzada sigmoidal (Asg), arenito com estratificação planar (Ap), arenito com acamamento ondulado (Ao) e arenito com estratificação quasi-planar (Aq). Os depósitos da AF2 são os mais expressivos nos afloramentos analisados, com espessura de até $5 \mathrm{~m}$, expostos nas margens do rio Jaú (pontos 3, 4 e 5, Fig. 1) e subordinadamente no rio Carabinani (ponto 7). A AF2 é composta por camadas de arenitos finos a médios bem selecionados com geometria de lobo sigmoidal, amalgamados e com falhas de crescimento locais. O lobo sigmoidal é destacado por superfícies de $4^{\mathrm{a}}$ ordem ou por camadas tabulares da fácies Pac da AF1 (Fig. 5B). A relação entre pelito e arenito configura ciclos coarsening upward de escala métrica. O lobo é dominado pela fácies Asg com toe set que lateralmente passa para laminação planar a ondulada e laminação cruzada cavalgante subcrítica (Fig. 5E). Acamamento maciço e a fácies Aq completam o quadro, o que caracteriza um lobo com estruturação complexa (Figs. 6A e B).

A estruturação complexa sugere a migração de barra arenosa para SW-SE em que o processo de tração dominava a região ativa enquanto a suspensão atuava na área periférica do lobo (Fig. 7). A fácies Asg indica formas de leito produzidas na região ativa sob regime de fluxo transicional a superior, com alta taxa de material em suspensão (RØe 1987, Figs. 6C, D, G e H).

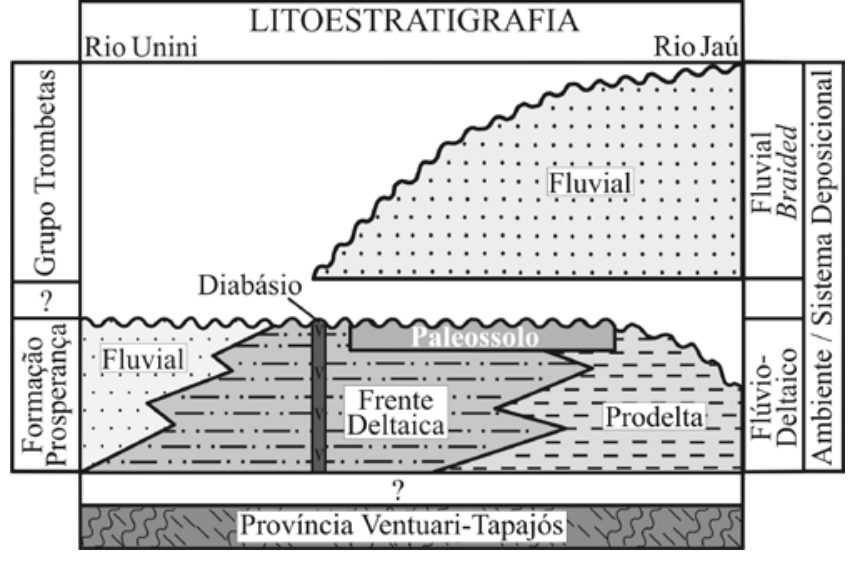

Figura 3 - Litoestratigrafia da região do baixo rio $\mathrm{Ne}$ gro entre a foz dos rios Unini e Jaú. Rochas flúvio-deltaicas da Formação Prosperança sotopõem a Província Ventuari-Tapajós. O topo da Formação Prosperança é marcado pelo desenvolvimento de perfis intempéricos (paleossolo) e por contato erosivo com as rochas do Grupo Trombetas da Bacia do Amazonas.

$\mathrm{Na}$ área marginal, a diminuição da energia de fluxo e da razão tração/suspensão gerava laminação ondulada e cruzada cavalgante (Reineck \& Singh 1980, Figs. 5E, $6 \mathrm{E}$ e H). Mud drapes, que recobrem a laminação ondulada, indicam períodos dominados por processos de suspensão (De Raaf et al. 1977). A exposição parcial da barra poderia gerar condições para remobilização de sedimentos por fluxo oscilatório relacionada à fácies $\mathrm{Aq}$ (Arnot 1993, Figs. 6E e G).

Lobos sigmoidais amalgamados com estruturação complexa são condizentes com a deposição de areias relacionadas com barras de desembocadura proximais em uma bacia com baixa inclinação e lâmina d'água rasa (Postma 1990). A geometria sigmóide foi gerada pelo processo de desaceleração do influxo sedimentar sobre uma bacia de baixa energia, por exemplo, uma laguna, lago ou mar epicontinental. $O$ padrão de paleocorrentes aparentemente oposta à fácies Asg coaduna com o processo de espraiamento de lobo relacionado a cortes com menos de $50^{\circ}$ em relação à direção principal da migração (Fig. 6H). Restritos lobos com geometria concave-up estão ligados ao aumento da contribuição da deposição a partir de suspensão e pela circulação reversa no lee side, em situações de baixa energia de fluxo na região marginal da barra de desembocadura (RØe 1987, Fig. 6F). A abundância de feições deformacionais (acamamento maciço, convolução na fácies Asg, falha de crescimento) e ciclos coarseningupward coadunam com ajustes gravitacionais/plásticos (Lowe 1975, Glover \& O’Beirne 1994, Bhattacharya 2006) em sistemas progradantes, comuns em ambientes com elevado influxo sedimentar, como barras de desembocadura na frente deltaica.

A influência fluvial é dominante e não existe indicação da ação de maré associado às barras de desem- 


\section{Tabela 1 - Fácies e processos deposicionais da sucessão sedimentar do baixo rio Negro.}

\begin{tabular}{c|c|c}
\hline Fácies & Descrição & Processo \\
\hline $\begin{array}{c}\text { Pelito laminado } \\
(\mathrm{Pl})\end{array}$ & $\begin{array}{c}\text { Camadas tabulares lateralmente contínuas por centenas de metros, } \\
\text { formadas por conjuntos de lâminas que alcançam 3cm. }\end{array}$ & $\begin{array}{c}\text { Deposição a partir de suspensão em ambientes com } \\
\text { baixa energia. }\end{array}$ \\
\hline $\begin{array}{c}\text { Pelito com feições } \\
\text { pedogenéticas }(\mathrm{Pp})\end{array}$ & $\begin{array}{c}\text { Camadas tabulares lateralmente contínuas por centenas de metros de } \\
\text { pelito arenoso. Apresenta horizontes mosqueados à rico em óxido/ } \\
\text { hidróxido de ferro. Estruturas pediformes e feições colunares. }\end{array}$ & $\begin{array}{c}\text { Deposição a partir de suspensão com aporte de } \\
\text { terrígenos. Exposição subaérea, pedogênese, } \\
\text { lixiviação e concentração de óxido/hirdóxido de ferro } \\
\text { por variação do lençol freático. }\end{array}$ \\
\hline
\end{tabular}

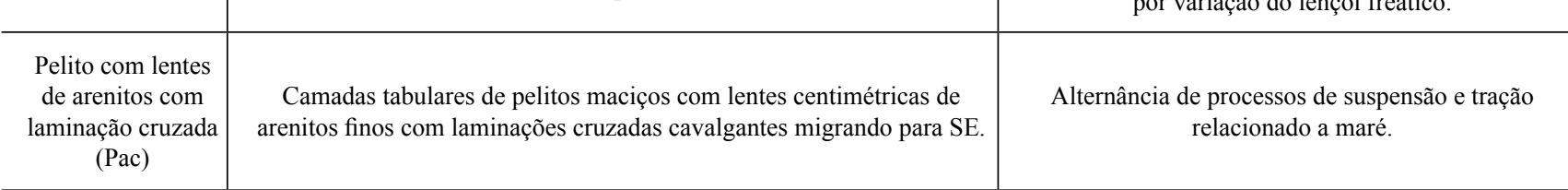

\begin{tabular}{|c|c|c|}
\hline $\begin{array}{l}\text { Ritmito arenito/ } \\
\text { pelito (Rap) }\end{array}$ & $\begin{array}{l}\text { Camadas tabulares com intercalações milimétricas entre arenitos finos e } \\
\text { pelitos. Cosets podem alcançar até } 0,5 \mathrm{~m} .\end{array}$ & Alternância de suspensão e tração. \\
\hline $\begin{array}{l}\text { Arenito com } \\
\text { estratificação planar } \\
\text { (Ap) }\end{array}$ & $\begin{array}{l}\text { Camadas tabulares e lenticulares de arenitos finos a grossos. Sets entre } \\
\qquad 0,2 \text { e } 0,3 \mathrm{~m} .\end{array}$ & $\begin{array}{l}\text { Migração de lençóis arenosos sob fluxo unidirecional } \\
\text { e regime de fluxo superior. }\end{array}$ \\
\hline $\begin{array}{c}\text { Arenito com } \\
\text { laminação cruzada } \\
\text { de baixo ângulo } \\
\text { (Ab) }\end{array}$ & $\begin{array}{l}\text { Camadas tabulares de arenitos finos e bem selecionados. Cosets com } \\
\text { inclinação máxima de } 10^{\circ} .\end{array}$ & Barras geradas pela ação do fluxo e refluxo de ondas. \\
\hline $\begin{array}{c}\text { Arenito com } \\
\text { estratificação } \\
\text { cruzada swaley (As) }\end{array}$ & $\begin{array}{l}\text { Camadas amalgamadas de arenitos finos a médios bem selecionados, } \\
\text { com estratificação cruzada swaley. Base côncava, erosiva e assimétrica } \\
\text { que lateralmente passam para laminação plano-paralela e truncamentos } \\
\text { de baixo ângulo. }\end{array}$ & $\begin{array}{c}\text { Fluxo combinado dominantemente oscilatório } \\
\text { de grande a média intensidade relacionado a } \\
\text { tempestades. }\end{array}$ \\
\hline $\begin{array}{l}\text { Arenito com } \\
\text { estratificação quasi- } \\
\operatorname{planar}(\mathrm{Aq})\end{array}$ & $\begin{array}{l}\text { Camadas lenticulares de arenitos finos a médios e bem selecionados. } \\
\text { Localmente apresenta truncamentos de baixo ângulo. }\end{array}$ & $\begin{array}{c}\text { Migração e agradação de formas de leito associadas } \\
\text { com relevo suave sob regime de fluxo oscilatório e/ } \\
\text { ou combinado. }\end{array}$ \\
\hline $\begin{array}{l}\text { Arenito com } \\
\text { acamamento } \\
\text { ondulado (Ao) }\end{array}$ & $\begin{array}{l}\text { Camadas tabulares e lenticulares decimétricas de arenitos finos, com } \\
\text { acamamento ondulado simétrico a assimétrico e amplitude de até } 4 \mathrm{~cm} \text {. } \\
\text { Lateralmente passam para laminação planar. Mud drapes recobrem as } \\
\text { ondulações. }\end{array}$ & $\begin{array}{c}\text { Deposição a partir da alternância entre fluxo } \\
\text { oscilatório e corrente unidirecional. Migração de } \\
\text { marcas onduladas e períodos de água parada ou } \\
\text { estofa. }\end{array}$ \\
\hline $\begin{array}{l}\text { Arenito com } \\
\text { estratificação } \\
\text { cruzada tangencial } \\
\quad \text { (Atg) }\end{array}$ & $\begin{array}{l}\text { Camadas tabulares decimétricas de arenitos finos migrando } \\
\text { preferencialmente para S-SW. Sets cruzados com inclinação máxima de } \\
15^{\circ} \text { que lateralmente tangenciam o bottom set. Mud drapes recobrem } \\
\text { sets cruzados. Superfícies de reativação, laminação cruzada cavalgante } \\
\text { subcrítica e acamamento maciço. }\end{array}$ & $\begin{array}{c}\text { Migração de sandwaves influenciada por correntes de } \\
\text { maré. Migração de marcas onduladas e processos de } \\
\text { suspensão. Liquefação localizada. }\end{array}$ \\
\hline $\begin{array}{l}\text { Arenito com } \\
\text { estratificação } \\
\text { cruzada sigmoidal } \\
\quad \text { (Asg) }\end{array}$ & $\begin{array}{c}\text { Camadas lenticulares lateralmente contínuas por dezenas de metros } \\
\text { de arenitos finos e bem selecionados que migram preferencialmente } \\
\text { para SW-SE. Foresets sigmoidais com mud drape, inclinação máxima } \\
\text { entre } 10-20^{\circ} \text { e limitados por superfícies de } 4^{\mathrm{a}} \text { ordem. Sets de até } 1,5 \mathrm{~m} \text {. } \\
\text { Toe sets exibe laminação plana a ondulada e laminação cruzada } \\
\text { cavalgante subcrítica. Deformação, acamamento maciço e raras falhas de } \\
\text { crescimento. }\end{array}$ & $\begin{array}{l}\text { Migração de formas de leito sob fluxo unidirecional } \\
\text { e regime de fluxo transicional a superior associado } \\
\text { com rápida desaceleração. Acamamento maciço } \\
\text { relacionado à liquefação por sobrecarga sedimentar } \\
\text { ou ausência de contraste granulométrico. Migração } \\
\text { de marcas onduladas e suspensão. }\end{array}$ \\
\hline $\begin{array}{c}\text { Arenito com } \\
\text { estratificação } \\
\text { cruzada tabular (At) }\end{array}$ & $\begin{array}{l}\text { Camadas tabulares métricas de arenitos médios a grossos com sets de até } \\
\qquad 0,6 \mathrm{~m} \text { e leve tendência fining-upward. }\end{array}$ & $\begin{array}{l}\text { Migração de formas de leito 2D sob fluxo } \\
\text { unidirecional e regime de fluxo inferior. Diminuição } \\
\text { do espaço de acomodação. }\end{array}$ \\
\hline $\begin{array}{l}\text { Arenito com } \\
\text { estratificação } \\
\text { cruzada acanalada } \\
\text { (Aa) }\end{array}$ & $\begin{array}{c}\text { Camadas lenticulares métricas com sets de até } 0,4 \mathrm{~m} \text { de arenitos médios } \\
\text { a grossos com migração para } \mathrm{SE} \text { e NW. Superfícies de reativação, } \\
\text { segregação de grãos grossos }(0,2-1,5 \mathrm{~mm}) \text { nos foresets, convoluções e } \\
\text { leve tendência fining-upward. }\end{array}$ & $\begin{array}{l}\text { Migração de formas de leito 3D sob fluxo } \\
\text { unidirecional e regime de fluxo inferior. Segregação } \\
\text { granulométrica relacionada ao transporte de } \\
\text { grãos grossos através formas de leito parasíticas. } \\
\text { Diminuição do espaço de acomodação. }\end{array}$ \\
\hline $\begin{array}{l}\text { Conglomerado } \\
\text { com estratificação } \\
\text { cruzada }(\mathrm{Cc})\end{array}$ & $\begin{array}{c}\text { Lentes de até } 0,25 \mathrm{~m} \text { de ortoconglomerado com seixos de quartzo } \\
\text { subangulosos a subarredondados, sustentado por matriz de areia média a } \\
\text { grossa. Estratificação cruzada incipientes. }\end{array}$ & $\begin{array}{l}\text { Migração de formas de leito sob fluxo unidirecional e } \\
\text { regime de fluxo inferior. }\end{array}$ \\
\hline
\end{tabular}




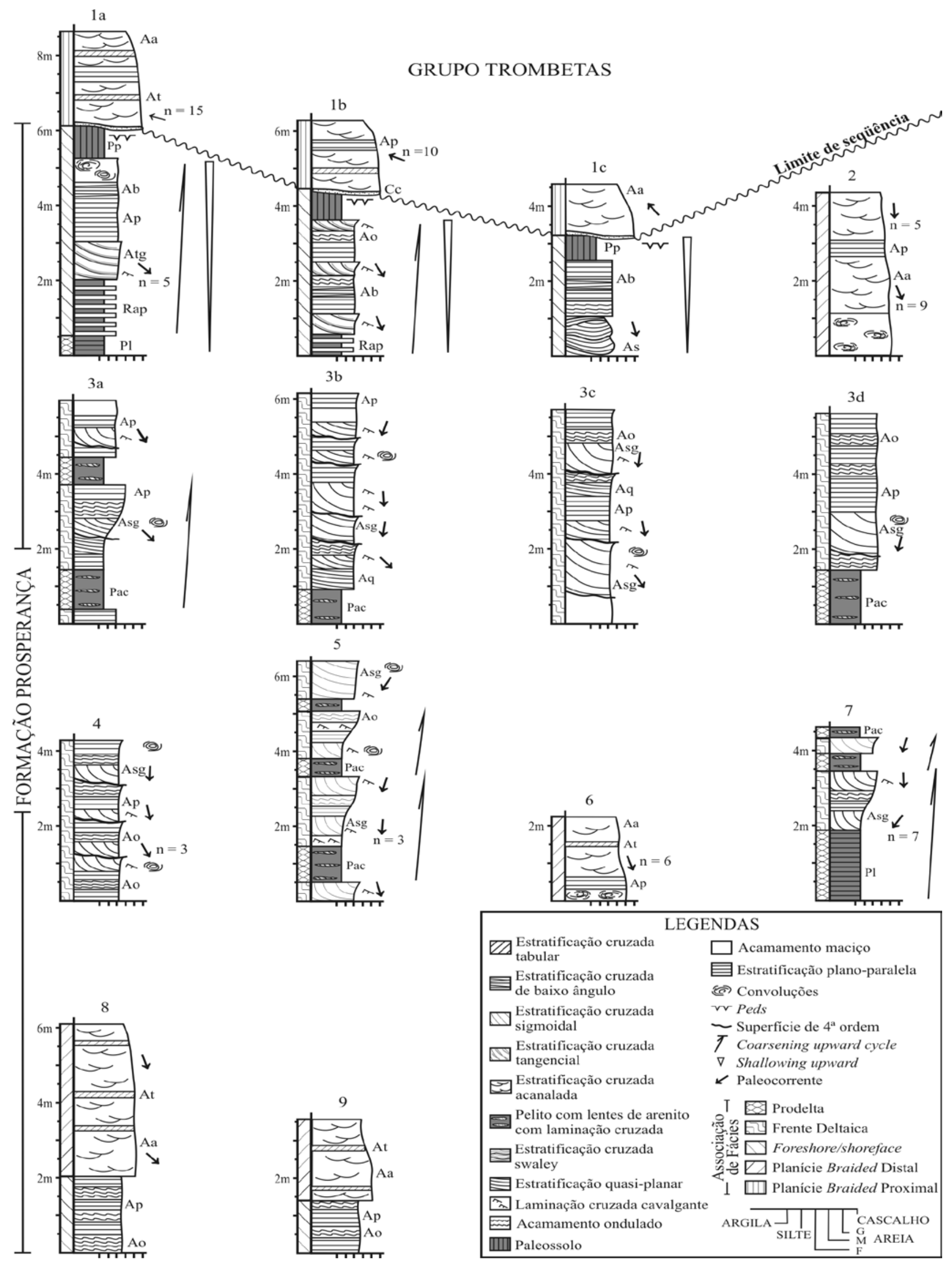

Figura 4 - Seções colunares da região do baixo rio Negro. O padrão de paleocorrentes entre as fácies da Formação Prosperança e do Grupo Trombetas são divergentes. A relação de contato entre essas unidades é representada por uma superficie erosiva (limite de seqüencia). 

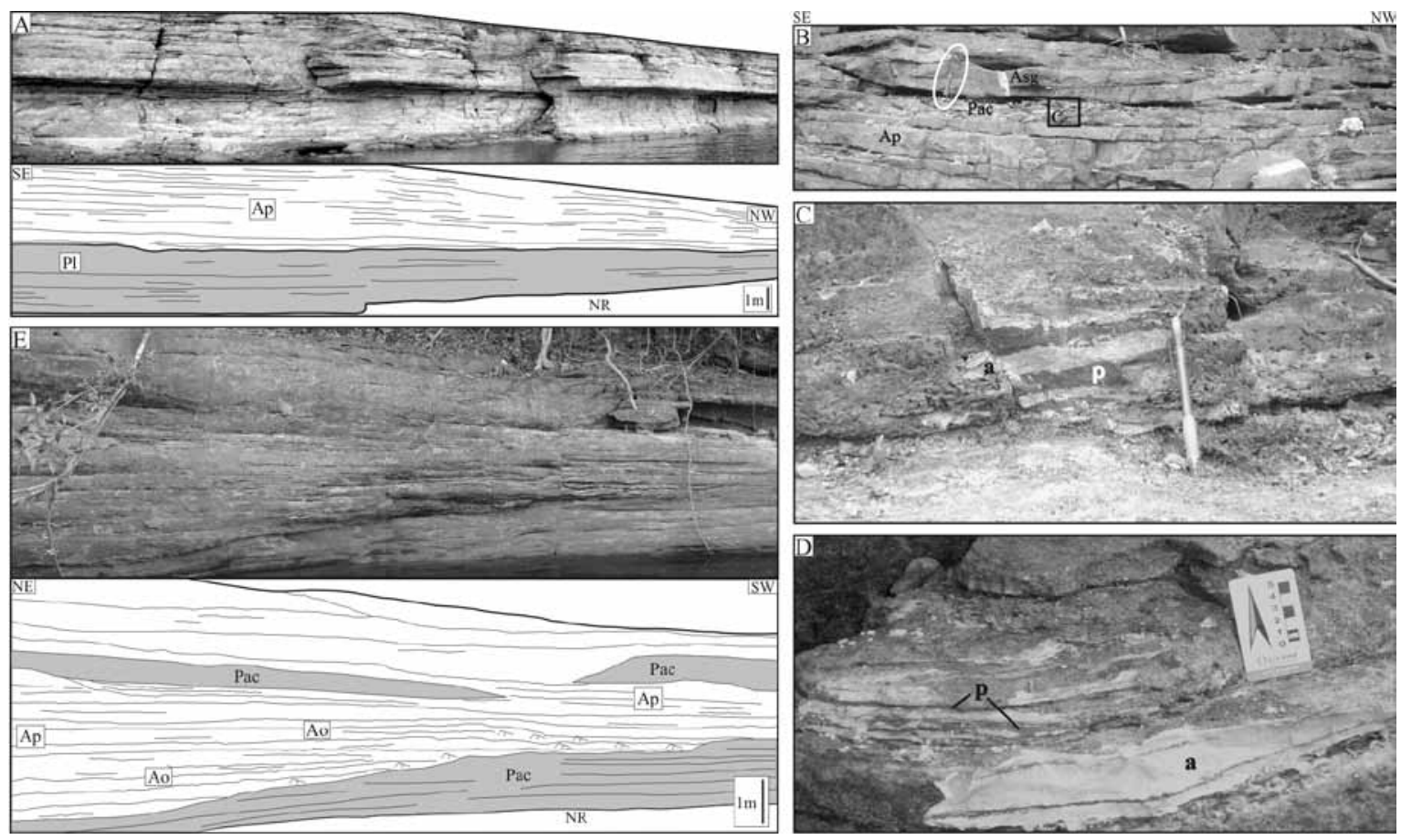

Figura 5 - Aspectos gerais da associação de fácies de prodelta. A) Corpos tabulares da fácies Pl sotopostos por depósitos de frente deltaica, representada pela fácies Ap (NR-nível do rio). B) Camadas tabulares da fácies Pac que por vezes destacam os lobos sigmóides da associação de fácies de frente deltaica (fácies Ap e Asg). Martelo geológico destacado por elipse. C e D) Detalhes da fácies Pac. Note que as lentes de arenito apresentam espessuras de até $4 \mathrm{~cm}$ (a-arenito com laminação cruzada e p- pelito). E) Esboço e relação espacial entre fácies de prodelta (Pac) e de frente deltaica (Ao e Ap). Observe que o contato entre as fácies Ao e Pac apresenta truncamentos de baixo ângulo e freqüente laminação cruzada cavalgante subcrítica no toe set da fácies Ao.

bocadura, o que poderia sugerir uma conexão oceânica. Assim, admite-se que a AF2 foi gerada por processos de desembocadura de canal proximal dominado por inércia/ fricção. Nesta situação, o elevado influxo sedimentar fornecido pelo sistema alimentador (distributário fluvial, AF4) desaguava em uma bacia receptora dominada por processos de suspensão e lâmina d'água rasa que localmente eram retrabalhados por fluxo oscilatório.

Associação de fácies 3 (AF3) - foreshore / shoreface A AF3 consiste em uma sucessão de camadas tabulares e lenticulares de arenitos finos a médios, ritmitos e pelitos arenosos, que alcançam $4 \mathrm{~m}$ de espessura, lateralmente contínuas por centenas de metros e expostas nas margens do rio Negro (Pontos 1 e 8, Fig. 1) e Unini (Ponto 9). É composta pelas fácies arenito com estratificação cruzada tangencial (Atg), arenito com estratificação cruzada swaley (As), arenito com acamamento ondulado (Ao), arenito com laminação cruzada de baixo ângulo (Ab), arenito com estratificação planar (Ap), ritmito arenito/pelito (Rap) e pelito com feições pedogenéticas (Pp) (Figs. 8, 9 e 10). Camadas lenticulares e amalgamadas com a fácies As ocorrem de forma restrita. A fácies As apresenta comprimento máximo de $5 \mathrm{~m}$ e amplitude de até $1,5 \mathrm{~m}$, onde predominam bases côncavas erosivas e assimétricas que lateralmente tendem para acamamento planar associado com a fácies Ap (Fig. 9). A fácies Pp juntamente com os depósitos da AF1 configuram topo e base de ciclos coarsening upward. São pelitos arenosos com horizontes intempéricos que gradam da base para o topo de mosqueado, ricos em óxido/hidróxido de ferro e com peds colunares (cf. Retallack 2001; Figs. 10A, B e D). O topo da fácies Pp apresenta contato do tipo erosivo com depósitos fluviais paleozóicos da AF5 (descritos posteriormente). Esta superfície erosiva (S) pode ser mapeada em afloramentos por centenas de metros ao longo das escarpas do rio Negro (Ponto 1). Neste caso, parte dos horizontes intempéricos (B e Bn) estão ausentes por erosão (Fig. 10C).

A fácies Rap e mud drapes nos foresets da fácies Atg sugerem atuação de correntes trativas alternadas com processos de suspensão. A freqüência de superfícies de reativação associadas à fácies Atg indica parada na sedimentação e assimetria do fluxo, com predominância da corrente dominante. Esta fácies é atribuída à migração de tidal sandwaves do tipo II (Allen 1980). Os valores de paleocorrentes obtidos nesta fácies, com direção predominante para $\mathrm{SE}$, são concordantes com os depósitos da AF2 e AF4 sugerindo que a corrente de maré vazante foi dominante, diminuindo o potencial de preservação das feições relacionadas à maré enchente (Fig. 7). O acamamento maciço e restritas convoluções relacionados à fácies Atg são produtos de liquefação esporádica em areias inconsolidadas (Lowe 1975). 

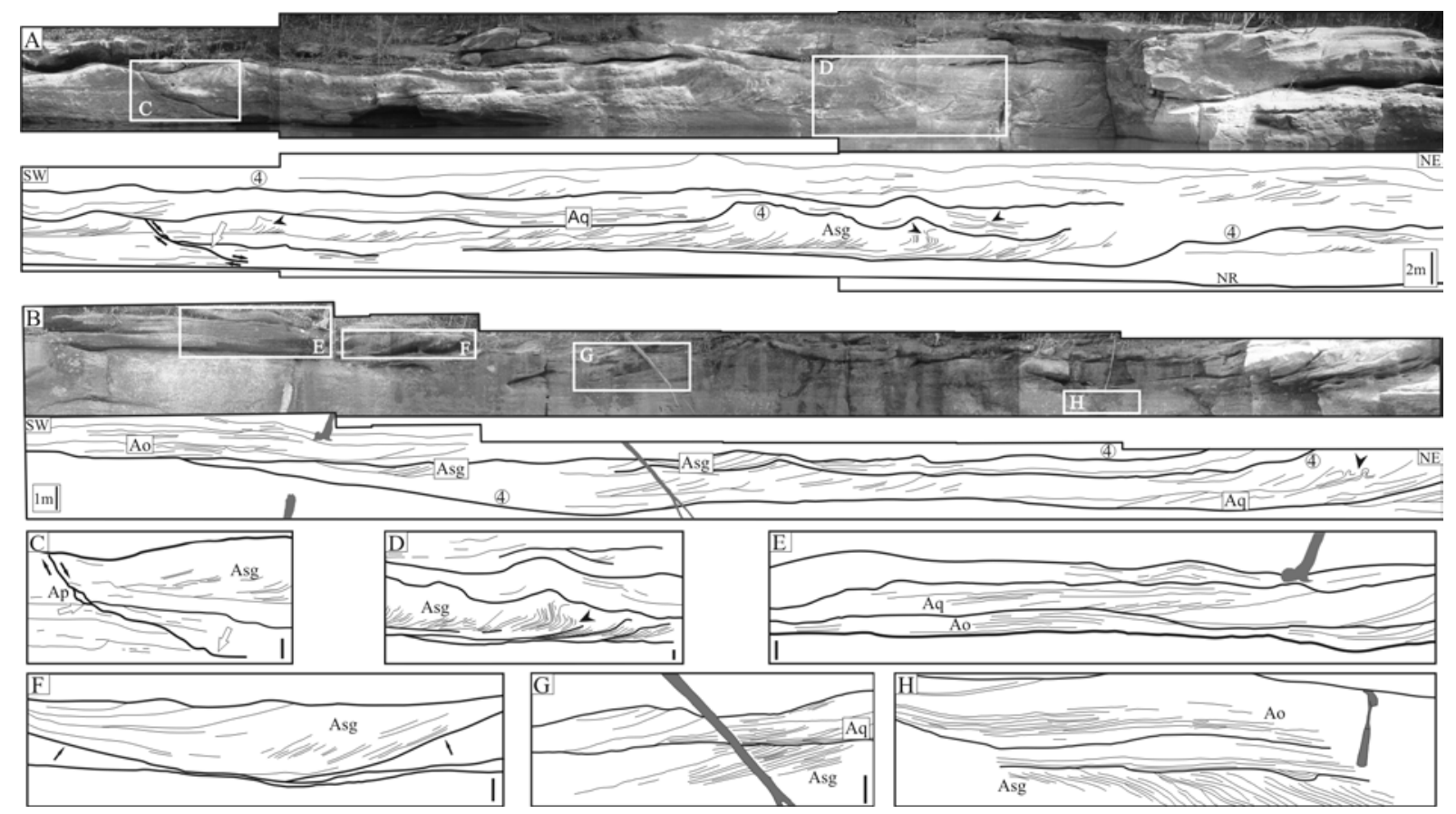

Figura 6 - Geometria deposicional e estruturação interna de depósitos da frente deltaica. A e B) Lobos amalgamados destacados por superficies de $4^{a}$ ordem (4) com estruturação interna dominada pela fácies Asg. A geometria dos lobos sigmoidais passam lateralmente para planares/lenticulares com as fácies Ap e Ao. Note a abundância de deformações como acamamento maciço, convolução (cunhas) e falha de crescimento (seta vazada). Escala vertical é igual à horizontal, NR- nível do rio. C) Falha de crescimento (seta vazada). As camadas tornam-se menos deformadas em direção a parte superior da falha. Setas fechadas indicam a dinâmica da deformação. D) Convolução da fácies Asg (cunha). E) Estruturação interna (fácies Aq e Ao) do lobo sigmoidal. F) Lobo com geometria côncava. Setas indicam a base côncava. G) Relação espacial das fácies Asg e Aq nos lobos arenosos. H) Estrato sigmoidal com padrão de paleocorrente oposto a predominante nestes depósitos (para SE). Barras verticais nas figuras $C-G$ igual a $50 \mathrm{~cm}$.

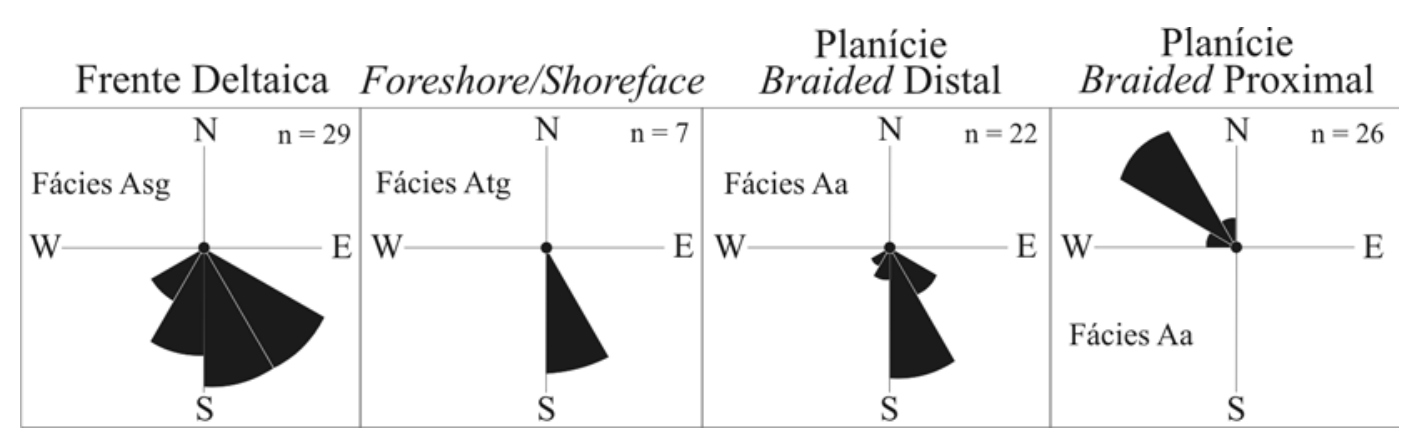

Figura 7 - Diagramas de roseta com os padrões de paleocorrentes das associações de fácies de frente deltaica, foreshore/shoreface, planicie braided distal e planície braided proximal. Note o padrão unimodal e que a direção das paleocorrentes dos depósitos de planície deltaica proximal está em contraste com as outras associações de fácies. Diagramas com intervalos de $30^{\circ}$.

Arenitos gerados sob regime de fluxo superior (fácies Ap), associados com arenitos produzidos sob condições de fluxo oscilatório (fácies Ao e Ab) e combinado (fácies As), condizem com áreas aplainadas, com lâmina d'água pouco espessa, sujeitas a ação de ondas de tempo bom e de tempestade, compatíveis com depósitos de face litorânea (Clifton 2006).
Os horizontes identificados na fácies Pp indicam processos de formação de solos relacionados a lixiviação e concentração de minerais, principalmente óxido-hidróxidos de ferro (horizontes C, Bo e B). As estruturas pediformes no horizonte $\mathrm{Bn}$ relatam a contração do solo ligado a exposição subaérea (Retallack 2001). A continuidade lateral das camadas da fácies Pp 

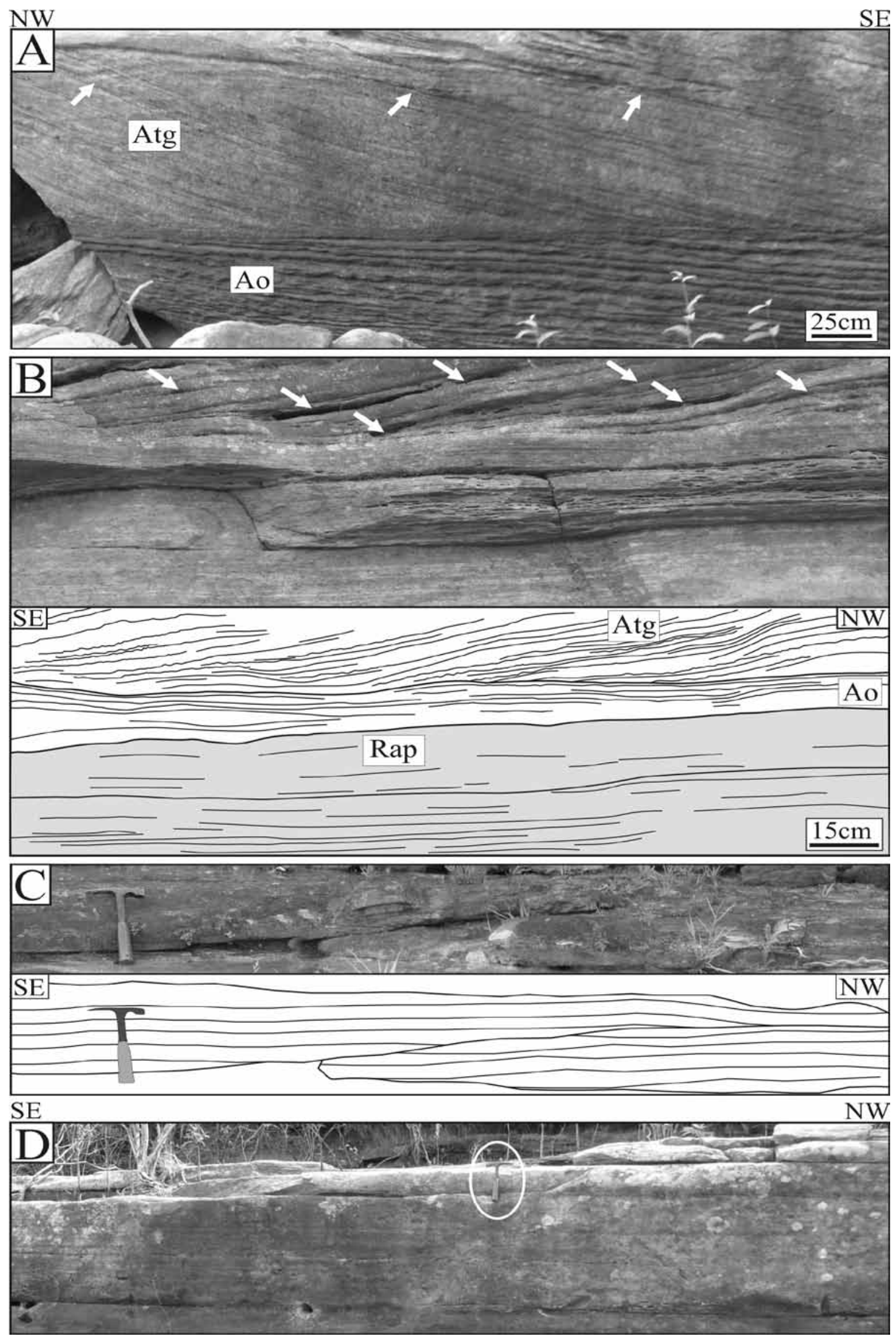

Figura 8 - Depósitos de foreshore/shoreface nas margens do rio Negro. A) Relação espacial entre as fácies Atg e Ao. Setas indicam superfícies de reativação. B) Detalhe das fácies Atg e Ao, estas sobrepostas à fácies Rap. O relevo negativo nos foresets da fácies Atg indica a retirada de mud drapes (setas). C) Aspecto geral e esboço de camadas tabulares com a fácies Ab. D) Laminações planares da fácies Ap. Martelo geológico destacado por elipse. 


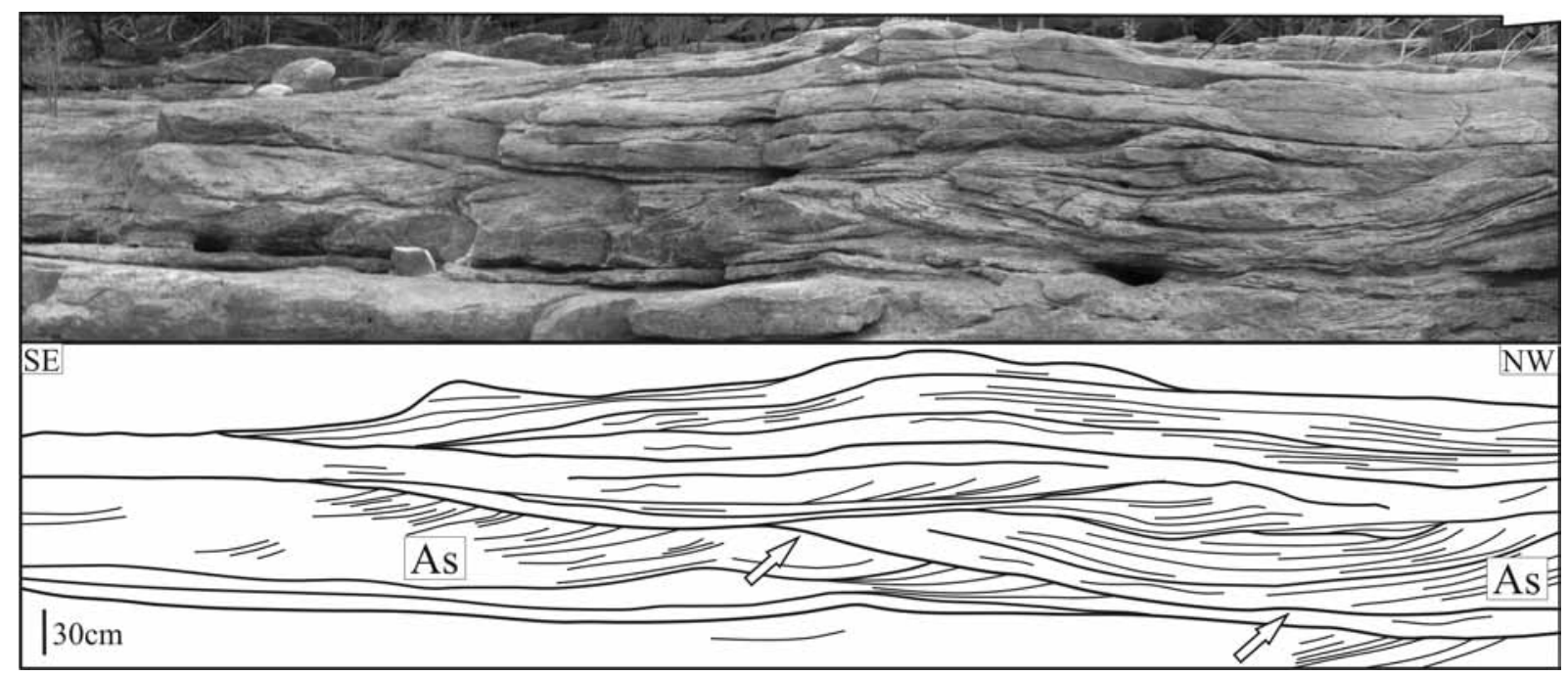

Figura 9 - Fácies As com base erosiva côncava e assimétrica (setas) que lateralmente passa para acamamento planar.
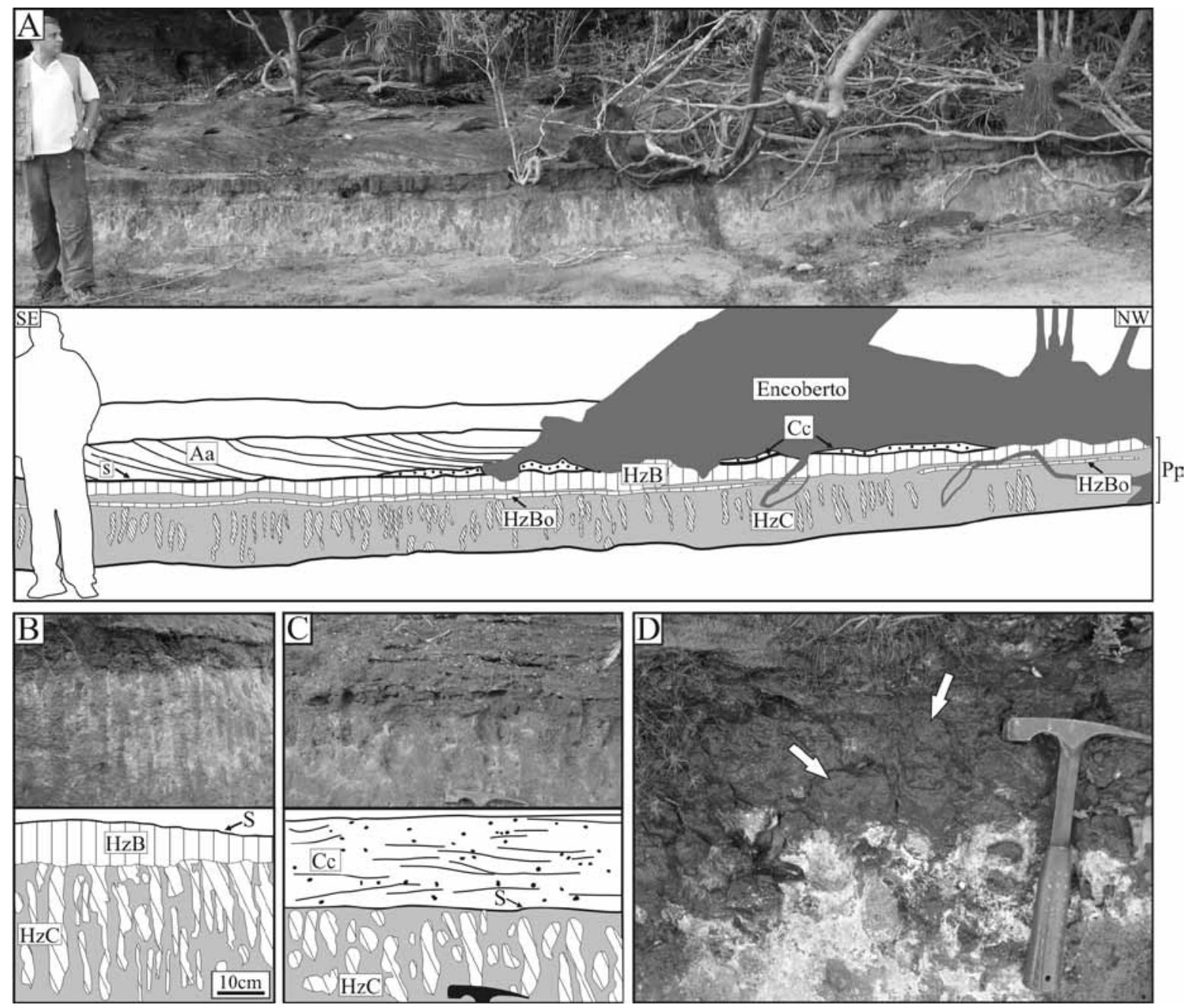

Figura 10 - Feições gerais da fácies Pp. A) Fácies Pp com os horizontes $\mathrm{HzC}$ (mosqueado), $\mathrm{HzB}$ e $\mathrm{HzBo}$ (ricos em óxido/hidróxido de ferro). A superfície erosiva (S) é recoberta pelas fácies $C$ c e Aa da AF5. B) Detalhe dos horizontes $\mathrm{HzC}$ e HzB. C) A superficie erosiva (S) marca a passagem de depósitos de foreshore/shoreface (fácies $P p$ ) e depósitos de planície braided proximal (fácies $C c$ ). Note que o horizonte $\mathrm{HzB}$ e parte do horizonte $\mathrm{HzC}$ foram erodidos pela fácies $\mathrm{Cc}$. D) Peds colunares $(\mathrm{HzBn})$ com topos dômicos indicados por setas. 
indica um ambiente de baixa energia, contínuo lateralmente por centenas de metros e dominado por processo de suspensão, compatível com laguna próximo à face litorânea. Lagunas são corpos d'água separados do mar aberto por cordões arenosos (ilhas barreiras) que estão relacionados a diversos subambientes costeiros (face litorânea, delta de maré, praia, mangue). Entretanto, a litologia da fácies $\mathrm{Pp}$ (pelitos arenosos), associada com depósitos formados pela migração de tidal sandwaves e de face litorânea, sugerem um ambiente costeiro, em parte protegido, onde processos de maré e ondas eram intensificados provavelmente em regiões abandonadas do delta. $\mathrm{O}$ constante rebaixamento da lâmina d'água da laguna e zona costeira propiciava a exposição dos depósitos por um intervalo de tempo razoavelmente longo, gerando intervalos de solos. De acordo com a classificação taxonômica de solos americana, os horizontes intempéricos estudados são produtos da formação de oxisolos (Soil Survey Staff 1975). Oxisolos são resultados de condições climáticas tropicais úmidas com idade de formação de dezenas a milhões de anos, por outro lado a presença de estruturas pediformes do horizonte $\mathrm{Bn}$ indica que a superfície do solo não era protegida e possivelmente sem vegetação (Retallack 2001).

Associação de fácies 4 (AF4) - planície braided distal Depósitos da AF4 englobam camadas tabulares de arenitos médios a grossos expostos de forma restrita nas margens dos rios Jaú, Negro e Unini, os dois últimos em locais próximos ao embasamento cristalino do Escudo das Guianas (Pontos 2, 6, 8 e 9, Fig. 1). Rochas da AF4 estão sotopostas a depósitos da AF3 e alcançam espessuras de 4m. A AF4 é composta pelas fácies arenito com estratificação cruzada acanalada (Aa), arenito com estratificação cruzada tabular (At) e arenito com estratificação planar (Ap), organizadas em ciclos de escala métrica com leve tendência fining-upward (Fig. 11 e 12A). É freqüente a segregação de grãos grossos nos foresets da fácies Aa, cujos sets diminuem de espessura para o topo dos ciclos (Figs. 11C e D). De forma secundária são encontradas as fácies Ap e At, esta última e assim como a fácies $\mathrm{Aa}$, apresenta leve tendência finning upward (Fig. 12A). Convoluções são feições presentes na fácies Aa, todavia essas deformações não são tão freqüentes quanto em depósitos da AF2 (Fig. 11E).

Arenitos médios a grossos das fácies Aa e At condizem com processos de migração de formas de leito com cristas sinuosas (3D) e reta (2D), encontradas em canalizações (Lindholm 1987, Collison \& Thompson 1989). Níveis de grossos nos foresets da fácies Aa são produtos da migração de material segregado a partir de formas de leito parasíticas sobre dunas, que respectivamente depositam material grosso e fino no lee side (Tucker 2003). Essas informações aliadas à leve tendência finning upward desses depósitos sugerem um ambiente compatível com depósitos de preenchimento de canais fluviais dominados por carga de fundo (bed load). Convoluções em camadas com a fácies Aa poderia indicar liquefação de sedimentos inconsolida- dos, sugerindo elevado fluxo sedimentar (Lowe 1975, Collinson \& Thompson 1989). Por outro lado, a fácies Ap estaria relacionada com a migração de lençóis arenosos (sheet flow) em locais do canal que favoreciam condições hidrodinâmicas com regime de fluxo superior, como em regiões com lâmina d'água com espessura máxima de $1 \mathrm{~m}$ (Cant \& Walker 1978, Reineck \& Singh 1980, Mial 1992). A granulometria geralmente grossa das fácies da AF4 em conjunto com a ausência de depósitos de inundação, abundante carga de fundo e predominância de paleocorrentes unidirecionais (SE) indicam o padrão fluvial tipo braided (Long, 1978, Miall 1977, 1992, Fig. 7). A relação espacial da AF4 com os depósitos da AF3 sugerem uma ambiência distal para esses depósitos fluviais.

\section{Associação de fácies 5 (AF5) - planície braided pro-} ximal Esta associação de fácies ocorre apenas nas proximidades da cidade de Airão (Ponto 1, Fig. 1), onde não ultrapassa espessuras de $2,5 \mathrm{~m}$. É constituída por arenitos médios a grossos e por ortoconglomerados que formam camadas lenticulares e sobrepõem de forma erosiva os depósitos da AF3 (Figs. 10A, C e 12B). A AF5 é representada pelas fácies conglomerado com estratificação cruzada $(\mathrm{Cc})$, arenito com estratificação cruzada acanalada (Aa), arenito com estratificação cruzada tabular (At) e arenito com estratificação planar (Ap), organizadas em ciclos finning upward de escala métrica. Ortoconglomerados da fácies $\mathrm{Cc}$ constituem a base desses depósitos. Estes erodem parcialmente os horizontes intempéricos da fácies $\mathrm{Pp}$ da AF3 (horizonte B) e destacam uma superfície que pode ser mapeada por centenas de metros desde a cidade de Airão em direção à jusante do rio Negro. A fácies Cc é sobreposta por arenitos médios a grossos internamente estruturados pelas fácies Aa, At e Ap (Figs. 10A e 12B). Níveis de segregação na fácies Aa aliados com a fácies Cc configuram as bases de ciclos finning upward. Medidas de paleocorrentes das fácies Aa e At indicam sentido para NW (Fig. 7).

Lentes da fácies $\mathrm{Cc}$ sugerem condições hidrodinâmicas de tração associados com a migração de barras longitudinais sob fluxo unidirecional e regime de fluxo superior (Postma 1990, Miall 1992). As camadas com a fácies Aa e At indicam processos de migração de formas de leito (cristas 3D e 2D, respectivamente) sob fluxo unidirecional e regime de fluxo inferior, análogo as fácies da AF4 (Lindholm 1987, Collison \& Thompson 1989). Superfícies de reativação na fácies Aa indicam períodos de parada e reativação da sedimentação das formas de leito, associados com mudanças na energia/ fluxo sedimentar nessa fácies (Tucker 2003). A fácies Ap sugere migração de lençóis arenosos sob regime de fluxo superior (Collinson \& Thompson 1989). A geometria e as estruturas desses depósitos são similares aos da AF4, o que sugerem processos sedimentares fluviais com elevada carga de fundo atribuído a uma planície braided. Quando comparada aos depósitos da AF4, apesar de ter a mesma interpretação paleoambiental, a AF5 difere pela paleocorrente oposta e por ter a base 

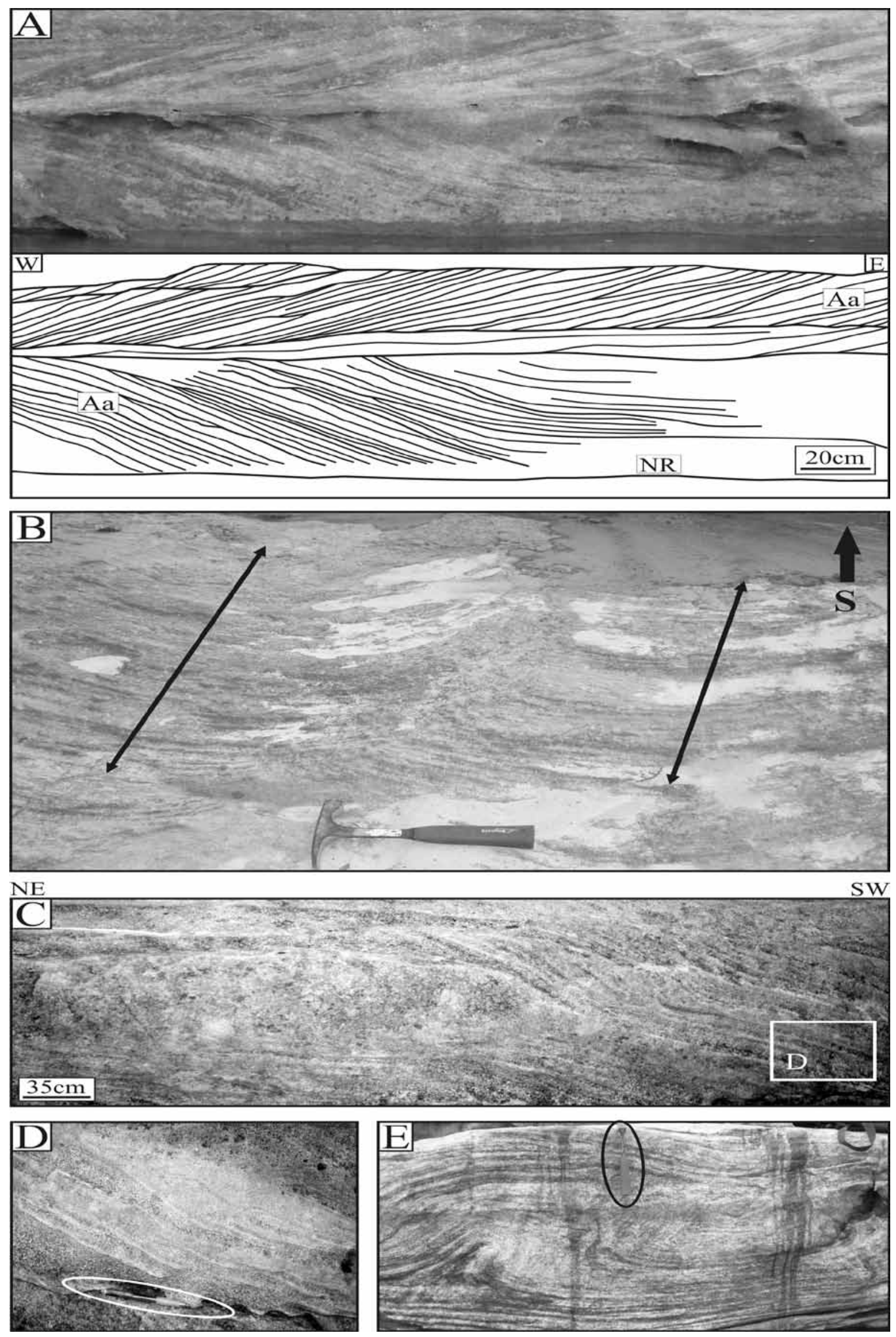

Figura 11 - Depósitos de planície braided distal. A) Corte transversal da fácies Aa. NR representa o nível do rio. B) Vista em planta da fácies Aa. Setas com pontas duplas representam o eixo de migração. C e D) Níveis de segregação de grossos associados à fácies Aa. Escala destacada por elipse. E) Convoluções associadas à fácies Aa. 


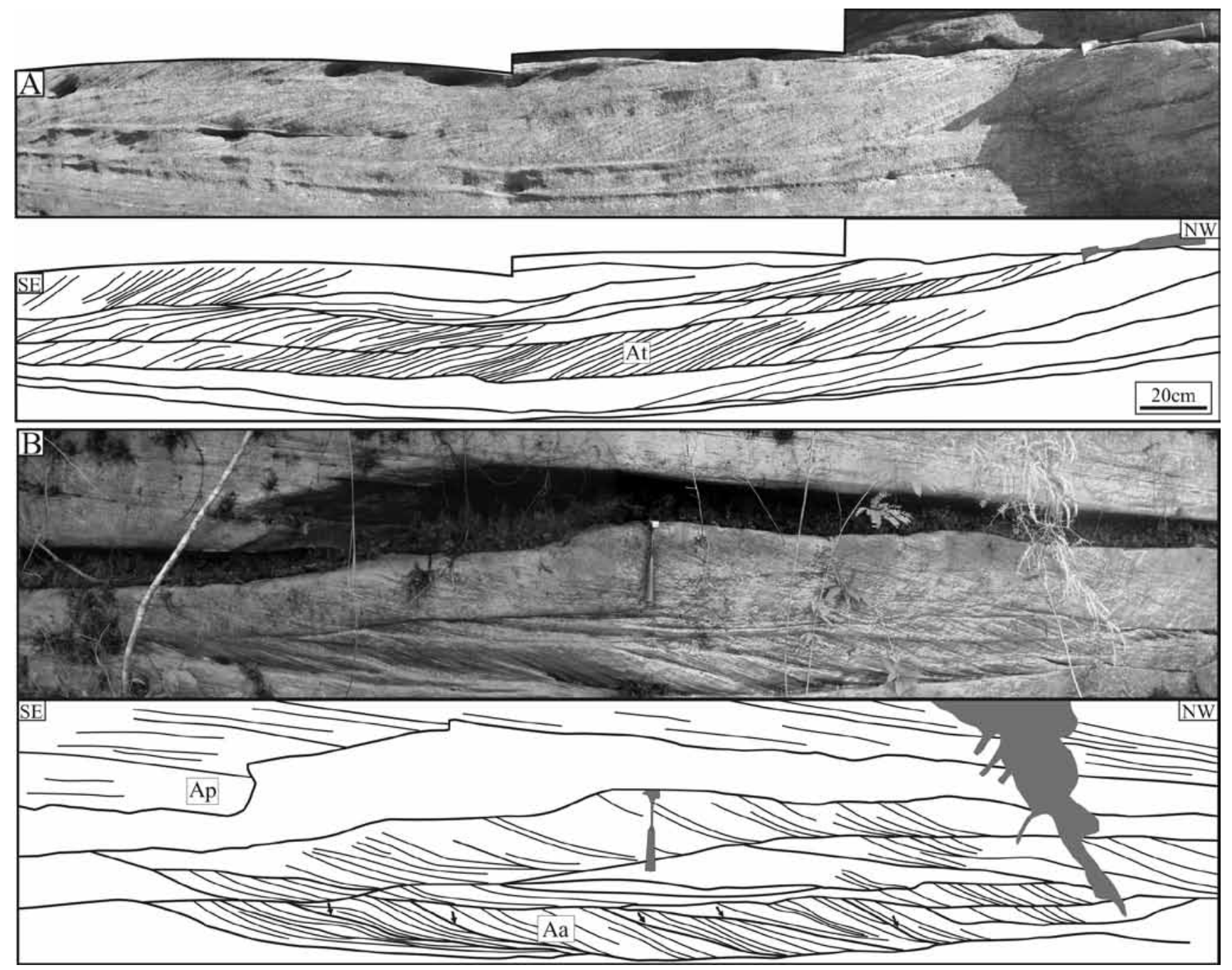

Figura 12 - Feição geral e esboço de camadas tabulares com as fácies At, Aa e Ap em afloramentos no rio Negro. A) Fácies At da associação de fácies 4. B) Depósitos da associação de fácies 5 . O sentido da paleocorrente na fácies $\mathrm{Aa}(\mathrm{NW})$ está em contraste em relação aos depósitos da figura A. Note na porção basal da fácies Aa várias superficies de reativação (setas).

limitada por uma superfície de discordância (Fig. 4, seções colunares1a, b e c; Fig. 7). Por conta desses fatores e pela correlação de unidades sedimentares que ocorrem na área estudada, considera-se que a AF5 representa provavelmente a porção basal de rochas do Grupo Trombetas da Bacia do Amazonas.

RECONSTITUIÇÃO PALEOAMBIENTAL A análise faciológica e estratigráfica realizada na região do baixo rio Negro permitiram reconhecer cinco associações de fácies que registram a implantação de sistemas flúvio-deltaico/costeiro (Formação Prosperança) e fluvial braided (Grupo Trombetas) na margem sul do Escudo das Guianas, formados em contextos tectônicos distintos.

Apesar das medidas de paleocorrentes indicarem que o sistema flúvio-deltaico/costeiro progradou para SE e o sistema fluvial braided paleozóico migrava para $\mathrm{NW}$, vale ressaltar que a reconstrução paleogeográfica do Neoproterozóico admitiu que o bloco Amazônico estivesse rotacionado quase $180^{\circ}$ e localizado nas proximidades do pólo sul (Tohver et al. 2006, Fig. 13). Sendo assim, as medidas de paleocorrentes obtidas nos estratos cruzados da Formação Prosperança estão invertidas.

A Formação Prosperança foi depositada em estruturas tipo gráben orientadas segundo NW-SE, seguindo a estruturação do Paleoproterozóico. Os grábens parecem refletir a última série de abatimentos ocorrida no Pré-cambriano em direção ao sul do Escudo das Guianas. A análise faciológica desta unidade revelou a progradação de distributários braided (AF4) em direção a NW, formando um sistema deltaico que incluía frente deltaica (AF2) e prodelta (AF1), desenvolvidos adjacentes a uma planície costeira (AF3) influenciada por maré e ondas de tempestade.

Deltas são sistemas progradantes que migram para um corpo d'água em repouso (p.e. mares, lagos e estuários) onde são reconhecidos processos sedimentares construtivos e destrutivos. Processos construtivos são representados por barras de desembocadura e os des- 


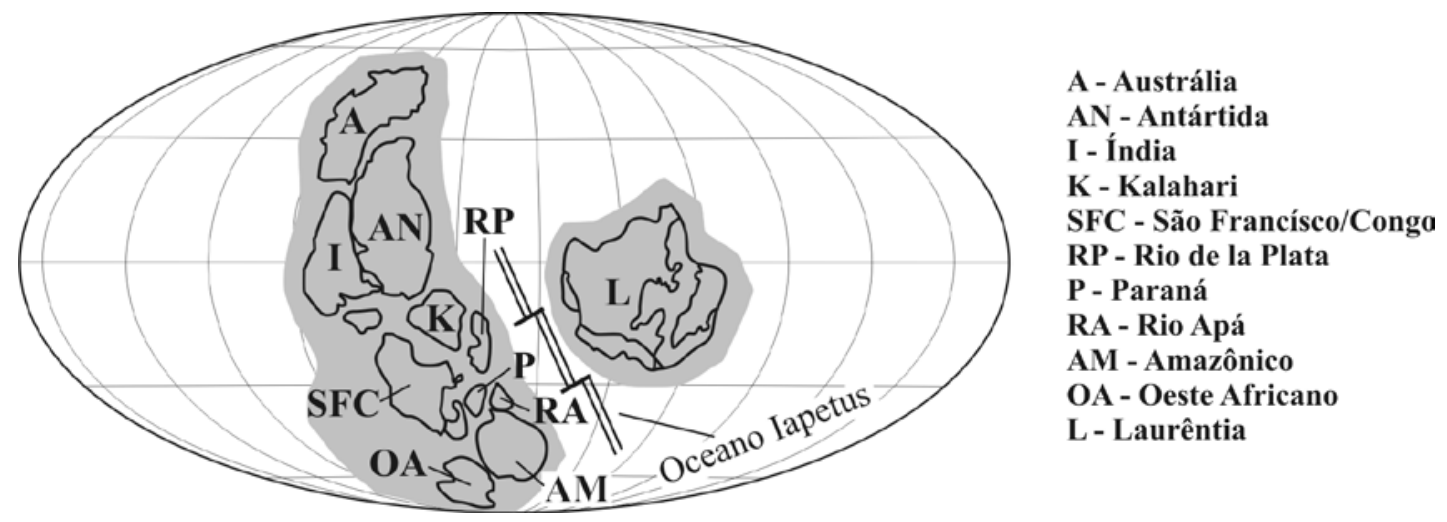

Figura 13 - Paleogeografia do Neoproterozóico com a disposição dos principais blocos continentais. A sucessão analisada pertence ao bloco Amazônico (AM) que estava rotacionado ( \pm $180^{\circ}$ ) e situado próximo a zona subpolar sul (Tohver et al. 2006).

trutivos pela formação de cordões arenosos, praias e lagunas, resultados da difusão dos sedimentos fornecidos pelo sistema alimentador por ondas, marés e correntes litorâneas (Postma 1990, Bhattacharya 2006). Enquanto o sistema fluvial fornecia sedimentos para as barras de desembocadura, lateralmente, depósitos abandonados do delta e mesmo fluviais eram retrabalhados na linha de costa.

Lobos deltaicos levemente inclinados, pouco espessos, com granulometria areia fina a média e depósitos de shoreface influenciados por fluxo oscilatório configuram perfis de deltas rasos (shallow profiles deltas) alimentados por sistemas fluviais do tipo $\mathrm{C}$, neste caso braided (Postma 1990). Esses tipos de lobos deltaicos possuem análogos modernos (Coleman 1982, 1988; delta do Mississippi) e no registro geológico (Elliot 1975; delta de Yoredale - Carbonífero). Devido ao baixo gradiente da bacia, esses tipos de deltas registram variações na dinâmica sedimentar na forma de inconformidades. Apesar de sistemas deltaicos serem influenciados tanto por processos autoclíclicos (p.e. mudanças no aporte sedimentar) quanto por alocíclicos (p.e. eustasia, avulsão e clima), a presença de uma importante superfície estratigráfica (S) aliada ao desenvolvimento de perfis intempéricos indicam que a provável razão foi influenciada por processos alocíclicos. Neste sentido, admite-se uma parada na sedimentação deltaica, exposição subaérea, seguida por condições alitizantes e formação de paleossolo. O paleossolo foi interpretado como oxissolo produzido em condições tropicais e úmidas (Soil Survey Staff 1975). Este está enraizado em depósitos pelíticos-arenosos que podem ter sido originalmente um sedimento depositado por decantação ou produto de alteração de rochas psamíticas ricas em minerais instáveis como o feldspato, o que sugere um tempo significativo de não deposição. Por conta disso, paleossolos têm sido usados como importantes marcadores estratigráficos na distinção entre unidades e para correlação (Charcosset et al. 2000, Retallack 2001, Ruskin \& Jordan 2007, Chakraborty \& Paul 2008).

Os depósitos da Formação Prosperança foram expostos pelo menos do limite Neoproterozóico-Cam- briano até o Ordoviciano, quando foram recobertos erosivamente pelos depósitos fluviais do Grupo Trombetas que migravam para SE, direção oposta ao sistema fluvial Prosperança. Rochas não intemperizadas do Grupo Trombetas sobrepostas ao paleossolo, restrito à associação de laguna (AF3), indicam pedogênese anterior ao Ordoviciano, ligada a própria evolução paleoambiental do sistema deltaico Prosperança.

A superfície de caráter erosivo (S) foi interpretada como limite de seqüência do tipo 1. Esta afirmativa é reforçada por padrões de paleocorrentes opostas entre os depósitos da Formação Prosperança e do Grupo Trombetas. Limites de seqüência podem ser caracterizados por: (1) discordâncias na borda da bacia, com evidências de erosão ou truncamentos de estratos e; (2) hiatos não deposicionais (Della Fávera 2001, Ribeiro 2001). Discordâncias na borda da bacia formam-se quando a queda do nível eustático resulta na transladação da linha de costa em direção a bacia. Nessa situação, o nível de base das drenagens sofre rebaixamento e o prisma costeiro é exposto e passa a ser erodido pelo sistema fluvial.

Deste modo, a reconstituição paleoambiental e evolutiva dos depósitos estudados podem ser divididas em três fases (Fig. 14): 1) No Neoproterozóico foi instalado na borda sul do Escudo das Guianas um sistema deltaico dominado por processos fluviais e influenciado por maré e ondas. Este delta era alimentado por um sistema fluvial braided que migrava para NW e tinha como áreas-fonte rochas no Escudo das Guianas; 2) Inversão da Bacia Prosperança formando o Arco de Purus, exposição e erosão de depósitos deltaicos e de planície costeira e; 3) Subsidência e início da formação da Bacia do Amazonas no Eopaleozóico seguida da progradação do sistema fluvial braided da base do Grupo Trombetas para SE, com áreas-fonte a NW.

CONCLUSÕES 1) A análise faciológica e estratigráfica de detalhe realizada em exposições da região do baixo rio Negro possibilitaram o reconhecimento de cinco associações de fácies integradas em um sistema flúvio-del- 


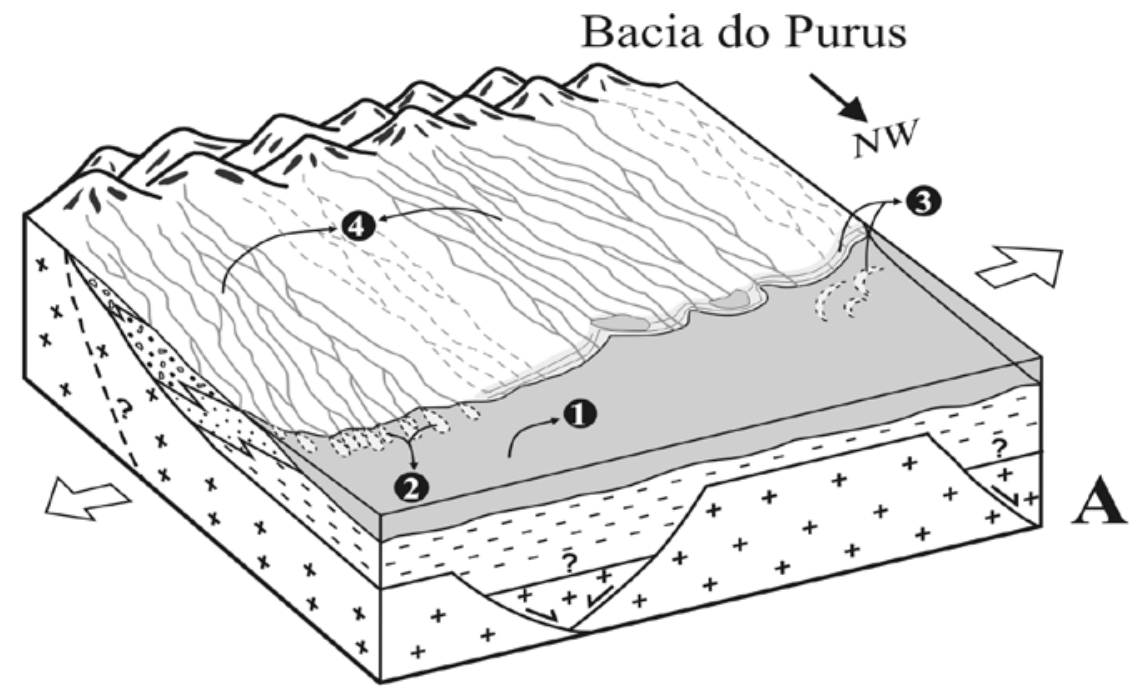

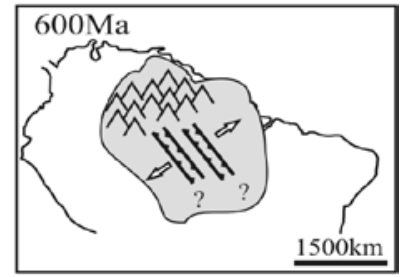

N Cadeia de Montanhas Trábens

$\Rightarrow$ Movimento Tectônico

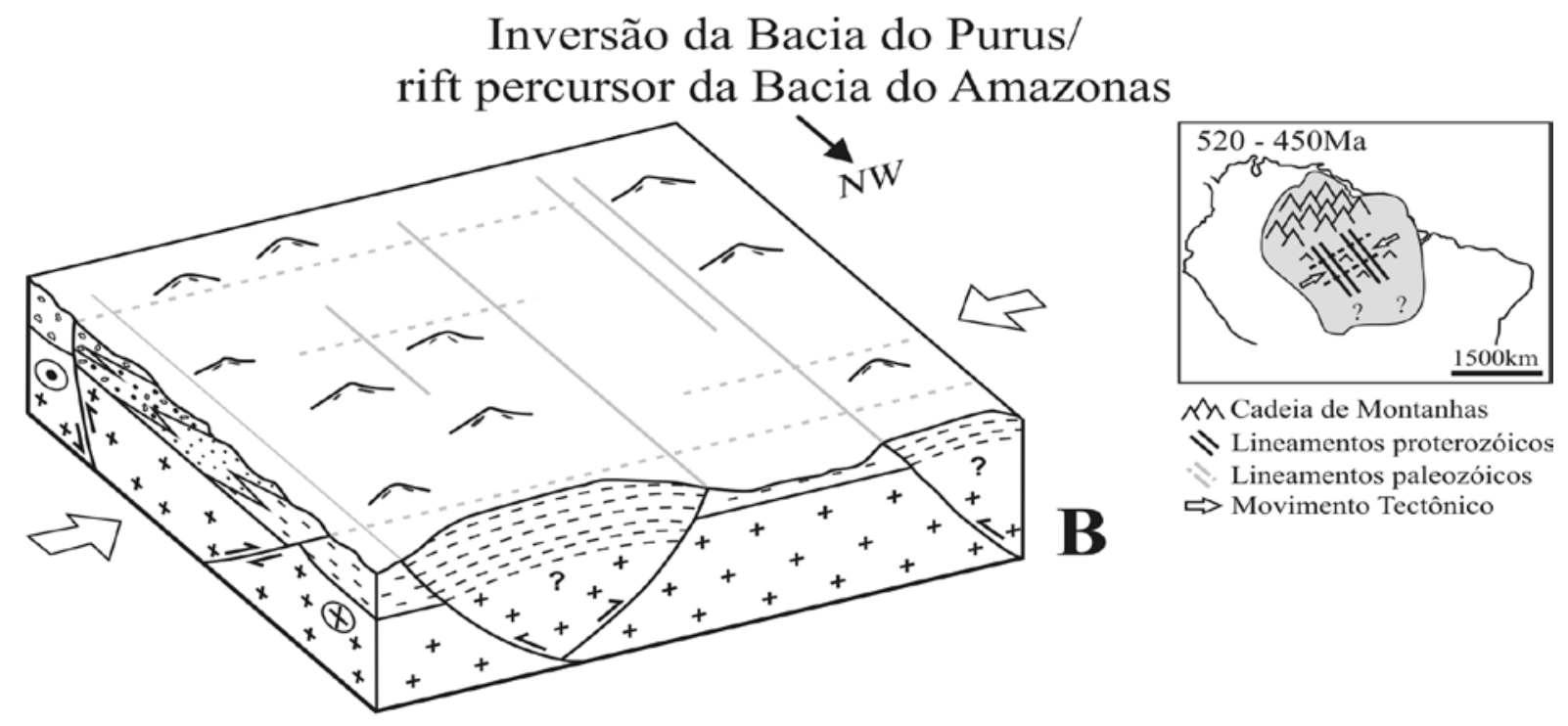

Implantação da Bacia do Amazonas

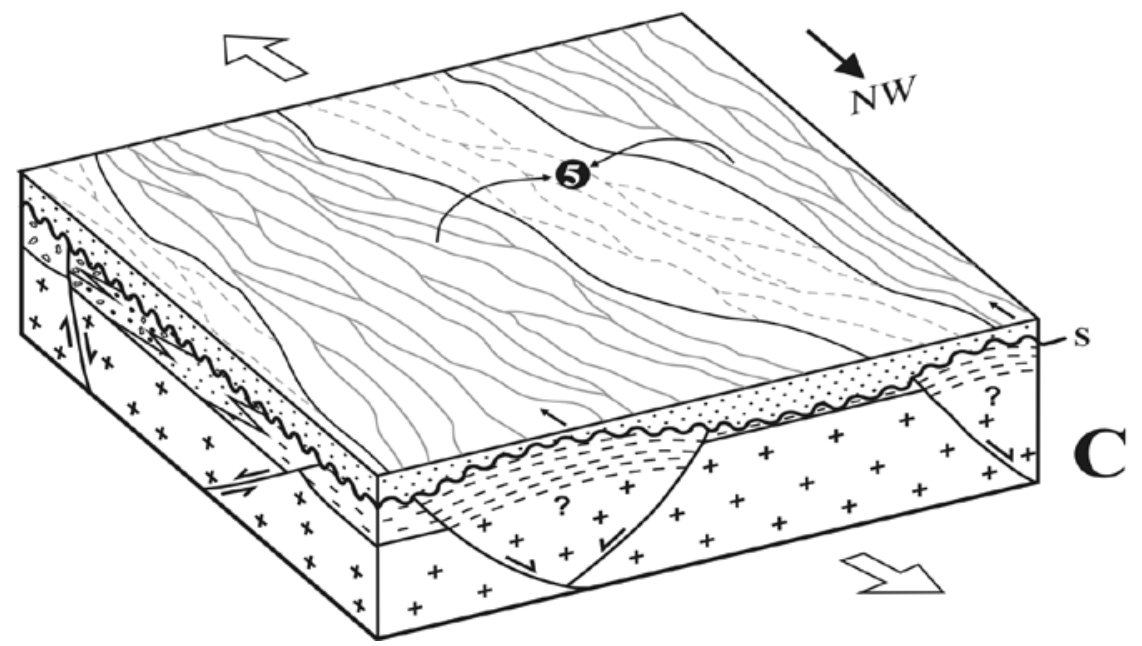

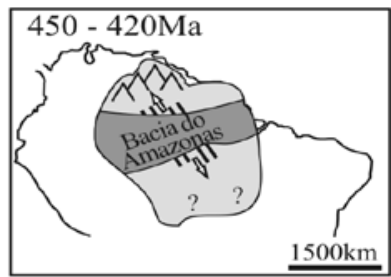

NM Cadeia de Montanhas $\checkmark$ Lineamentos proterozóicos $\Rightarrow$ Movimento Tectônico

Figura 14 - Reconstituição paleoambiental e evolutiva dos depósitos da região do baixo rio Negro. A) No Neoproterozóico foi implantado um sistema deltaico que progradava para NW e era alimentado por um sistema fluvial braided. B) Inversão da Bacia do Purus e formação do rift percursor da Bacia do Amazonas seguido de exposição/erosão de depósitos da Formação Prosperança. C) Progradação do sistema fluvial braided do Grupo Trombetas que migrava para SE, formando assim um limite de seqüência (S). 1- Prodelta (AF1), 2- Frente deltaica (AF2), 3-Foreshore/shoreface (AF3), 4- Planície braided distal (AF4) e 5-Planície braide proximal (AF5). 
taico neoproterozóico e fluvial eopaleozóico. A ambiência flúvio-deltaica em depósitos da Formação Prosperança reforça a natureza costeira proposta por Nogueira \& Soares (1996) e auxilia na melhor compreensão da evolução sedimentar na margem sul do Escudo das Guianas.

2) O sistema flúvio-deltaico era alimentado por canais fluviais braided que migrava para NW e tinham como área-fonte rochas do Escudo das Guianas à SE. Os sedimentos trazidos por esse sistema fluvial eram depositados em uma bacia sem talude e com lâmina d'água rasa na forma de barras de desembocadura. Ao longo da linha de costa, em regiões abandonadas do delta e em planícies costeiras adjacentes, os sedimentos eram localmente retrabalhados pela ação de maré, onda de tempo bom e de tempestade.

3) A formação de oxissolo em depósitos da Formação Prosperança manifesta-se como o primeiro registro pré-cambriano de condições tropicais úmidas no Cráton Amazônico.
4) A inversão da Bacia Prosperança propiciou a formação do Arco de Purus e formação do rift percursor da Bacia do Amazonas. Posteriormente o Arco de Purus foi parcialmente erodido pelo sistema fluvial do Grupo Trombetas que migrava para SE e resultou na formação de um limite de seqüência.

Agradecimentos A Coordenação de Aperfeiçoamento de Pessoal do Ensino Superior (CAPES) pela concessão da bolsa de mestrado, a Dra. Lucieth Cruz Vieira (UNB) e Nelson Reis (Serviço Geológico do BrasilCPRM/Manaus) pelo auxílio e discussões na etapa de campo. Ao IBAMA - ICMBio pela autorização para atividades com finalidade científica (\#17740-1) e INCT de Geociências da Amazônia (CNPq/MCT/FAPESPA 573733/2008-2) pelo financiamento de parte desta pesquisa. Os agradecimentos são extensivos aos revisores anônimos pelas sugestões ao texto final.

\section{Referências}

Allen J.R.L. 1980. Sand waves; a model of origin and internal structure. Sedimentary Geology, 26:281-328.

Arnott R.W.C. 1993. Quasi-planar-laminated sandstone bed of the Lower Cretaceous Bootlegger Member, NorthCentral Montana: evidence of combined-flow sedimentation. Journal of Sedimentary Petrology, 63:488-494.

Bhattacharya J. P. 2006. Deltas. In: Posamentier H.W. \& Walker R.G. (eds.) Facies model revised. Special Publication, 84, SEMP, p. 237-292.

Cant D.J. \& Walker R.G. 1978. Fluvial process and facies sequences in the sandy braided South Saskatchewan River, Canada. Sedimentology, 25:625-648.

Caputo M.V., Rodrigues R., Vasconcelos D.N.N. 1972. Nomenclatura estratigráfica da Bacia do Amazonas - histórico e atualizações. In: SBG, Congresso Brasileiro de Geologia, 26, Anais, 3:35-46.

Castro J.C., Eiras J.F., Caputo M.V. 1988. Paleozóico do Rio Tapajós. In: SBG, Congresso Brasileiro de Geologia, 35, Roteiro das excursões, $\mathrm{n}^{\circ}$ 8, p. 27-44.

Chakraborty P. P. \& Paul S. 2008. Forced regressive wedges on a Neoproterozoic siliciclastic shelf: Chandarpur Group, central India. Precambrian Research, 182:227247.

Charcosset P., Combes P., Peybernès B., Ciszak R., Lopez M. 2000. Pedogenic and Karstic features at the boundaries of Bathonian depositional sequences in the Grands Causses Area (southern France): stratigraphic implication. Journal of Sedimentary Research, 70(1):255-264.

Clifton H.E. 2006. A reexamination of facies models for clastic shorelines. In: H. W. Posamentier \& R. G. Walker (eds.) Facies model revised. Special Publication, 84, SEMP, p.: 293-337.

Coleman J.M. 1982. Deltas, processes of deposition and models for exploration. Boston, International Human Resources Development Corporation, 124 p.

Coleman J.M. 1988. Dynamic changes and processes in the Mississippi River delta. Bull. Geol. Soc. Am, 100:999-
1015.

Collinson D.B. \& Thompson J.B. 1989. Sedimentary structures, $2^{\mathrm{a}}$ ed., London, Unwin Hyman, 207 p.

CPRM 2002. Geologia e recursos minerais da Amazônia brasileira, região cratônica. SIG-Brasil, Mapa escala 1:750.000, CD-Rom.

Cunha P.R.C., Melo J.H.G., Silva O.B. 2007. Bacia do Amazonas. Boletim de Geociências da Petrobras, 15(2):227251.

De Raaf J.F.M., Boersma J.R., Van Gelder A. 1977. Wavegenerated structures and sequences from a shallow marine succession, Lower Carboniferous, County Cork, Ireland. Sedimentology, 24:451-483.

Della Fávera J. 2001. Fundamentos da estratigrafia moderna. Rio de Janeiro, UFRJ, 264 p.

Eiras J.F. 1996. Influência tectônica do Arco de Carauari na sedimentação fanerozóica da Bacia do Solimões, norte do Brasil. In: SBG, Congresso Brasileiro de Geologia, 39, Anais, p. 52-53.

Elliott T. 1975. The sedimentary history of a delta lobe from a Yoredale (Carboniferous) cyclothem. Proc. Yorkshire Geol. Soc., 40:505-536.

Glover B.W. \& O’Beirne A.M. 1994. Anatomy, hydrodynamic and deposition setting of a Westiphalian lacustrine delta complex, West Midlands, England. Sedimentology, 41:115-132.

Hoorn C., Roddaz M., Dino R., Soares E., Uba C., OchoaLozano D., Mapes D. 2010. The Amazonian Craton and its influence on past fluvial systems. In: Hoorn C. \& Wesselingh F. (eds.) Amazonia: landscape and species evolution - a look into the past. Wiley-Blackwell, p. 103-122.

Lindholm R. C. 1987. A practical approach to sedimentology. London, Allen \& Unwin, $276 \mathrm{p}$.

Long D.G.F. 1978. Proterozoic stream deposits: some problems of recognition and interpretation of ancient sandy fluvial systems. In: Miall A.D. (ed.) Fluvial Sedimen- 
tology, Memoir 5 Calgary, Can. Soc. Pet. Geol, p. 313341.

Lowe D.R. 1975. Water scape structures in coarser-grainded sediments. Sedimentology, 22:157-204.

Mapes R.W. 2009. Past and present provenance of the Amazon river. Chapel Hill: University of North Carolina. Tese de Doutoramento, Department of Geological Sciences, North Caroline University, 185 p.

Miall A.D. 1977. A review of the braided river depositional environment. Earth Science Reviews, 13:1-62.

Miall A.D. 1992. Alluvial deposits. In: Walker R.G. \& James N.P. (eds.) Facies model: response to sea level change. Geological Association of Canada, p. 119-142.

Montavão R.M. \& Bezerra P.E.L. 1985. Evolução tectônica do Cráton Amazônico (Amazônia Legal) durante o Arqueano e Proterozóico. In: SBG, Simpósio de Geologia da Amazônia, 2, Anais, p. 282-294.

Nogueira A.C.R. \& Soares E.A.A. 1996. Fácies sedimentares da Formação Prosperança, Proterozóico Superior da Bacia do Amazonas, ao norte da cidade de Manaus. In: SBG, Simpósio de Geologia da Amazônia, 5, Resumos expandidos, p. 214-216.

Postma G. 1990. Depositional architecture and facies of river and fan deltas: a synthesis. In: Colella A. \& Prior D.B. (eds.) Coarser-grained deltas. Special Publication $n^{\circ} 10$ of International Association of Sedimentologists, Blackwell Scientific Publication, p. 29-74.

Reineck H.E. \& Singh I.B. 1980. Deposicional Sedimentary Environments. New York, Springer-Verlag, 551 p.

Retallack G.J. 2001. Soils of the past: an introduction to paleopedology. London, Unwin, $520 \mathrm{p}$.

Ribeiro H.J.P.S. 2001. Fundamentos de estratigrafia de seqüências. In: Ribeiro H.J.P.S. (org.) Estratigrafia de seqüencias - fundamentos e aplicações. UNISINOS, p.
99-134.

RØe S. 1987. Cross-strata and bedforms of probable transitional dune to upper-stage plane-bed origin from a Late PreCambrian fluvial sandstone, northern Norway. Sedimentology, 34:89-101.

Ruskin B.G. \& Jordan T.E. 2007. Climate change across continental sequence boundaries: paleopedology and lithofacies of Iglesia Bason, Northwestern Argentina. Journal of Sedimentary Research, 77:661-679.

Soil Survey Staff 1975. Soil taxonomy, a basic system of soil classification for making and interpreting soil surveys: handbook. U.S. Department of Agriculture, 436 p.

Tohver E., D’Agrella-Filho M.S., Trindade R.I.F. 2006. Paleomagnetic record of Africa and South America for the 1200-500Ma interval, and evaluation of Rodinia and Gondwana assemblies. Precambrian Research, 147:193222.

Tucker M.E. 2003. Sedimentary rocks in the field: the geological field guide series, $3^{\mathrm{a}}$ ed., Chichester, Wiley, 234 p.

Walker R.G. 1990. Facies modelling and sequence stratigraphy. Journal of Sedimentary Petrology, 60:777-786.

Walker R.G. 1992. Facies, facies model and modern stratigraphic concepts. In: Walker R.G. \& James N.P. (eds.) Facies model: response to sea level change. Geological Association of Canada, p.1-14.

Wanderley Filho J. R. 1991. Evolução estrutural da Bacia do Amazonas e sua correlação com o embasamento. Dissertação de Mestrado, Centro de Geociências, Universidade Federal do Pará, 125 p.

Manuscrito ID 17057

Submetido em 18 de março de 2010 Aceito em 22 de novembro de 2010 